\title{
Achieve Continuous Injection of Solid Fuels into Advanced Combustion System Pressures
}

\section{FINAL REPORT}

\author{
Reporting Period Start Date: October $15^{\text {th }} 2002$ \\ Reporting Period End Date: June 11 ${ }^{\text {th }}, 2007$ \\ Principal Authors: Derek L. Aldred \\ Timothy Saunders
}

Issued: Dec, 2007

Project \# DE-FC26-02NT41439

Stamet Incorporated

8210 Lankershim Blvd., Unit 9

North Hollywood, CA 91605 


\section{$\underline{\text { Disclaimer }}$}

This report was prepared as an account of work sponsored by an agency of the United States Government. Neither the United States Government nor any agency thereof, nor any of their employees, makes any warranty, express or implied, or assumes any legal liability or responsibility for the accuracy, completeness, or usefulness of any information, apparatus, product or process disclosed, or represents that its use would not infringe privately owned rights. Reference herein to any specific commercial product, process or service by trade name, trademark, manufacturer, or otherwise does not necessarily constitute or imply its endorsement, recommendation, or favoring by the United States Government or any agency thereof. The views and opinions of authors expressed herein do not necessarily state or reflect those of the United States Government or any agency thereof. 
DE-FC26-02NT41439

\begin{abstract}
$\underline{\text { Abstract }}$
The overall objective of this project is the development of a mechanical rotary-disk feeder, known as the Stamet Posimetric ${ }^{\circledR}$ High Pressure Solids Feeder System, to demonstrate feeding of dry granular coal continuously and controllably into pressurized environments. The initial award was granted in 2 phases, demonstrating continuous feeding into 300psi and 500psi respectively. During the course of the project, driven by the higher projected operating pressures proposed for next generation coal gasification systems, a further 2 phases were added. Phase III to demonstrate continuous injection into 1,000psi was approved in July 2005, and, contingent on Phase III success, Phase IV was planned to reach the 1,300psi pressure level.
\end{abstract}

The first task was to review materials handling experience in pressurized operations as it related to the target pressures for this project, and review existing coal preparation processes and specifications currently used in advanced combustion systems. Samples of existing fuel materials were obtained and tested to evaluate flow, sealing and friction properties. This provided input data for use in the design of the Stamet Feeders for the project, and ensured that the material specification used met the requirements of advanced combustion \& gasification systems. Ultimately, Powder River Basin coal provided by the PSDF facility in Wilsonville, AL was used as the basis for the feeder design and test program.

Based on the material property information, a Phase I feeder system was designed and built to accomplish feeding the coal to an intermediate pressure up to $21 \mathrm{~kg} / \mathrm{cm}^{2}$ (300 psi) at feed rates of approximately 100 kilograms (220lbs) per hour. The pump \& motor system was installed in a custom built test rig comprising an inlet vessel containing an active live-wall hopper mounted in a support frame, transition into the pump inlet, transition from pump outlet and a receiver vessel containing a receiver drum supported on weigh cells. All pressure containment on the rig was rated for the final pressure requirement of $35 \mathrm{~kg} / \mathrm{cm}^{2}$ (500psi).

A program of testing and modification was carried out in Stamet's facility in CA, culminating in successful feeding of coal into the Phase 1 target of $21 \mathrm{~kg} / \mathrm{cm}^{2}(300 \mathrm{psi})$ gas pressure in December 2003. Further testing was carried out at CQ Inc's facility in Homer City, PA, providing longer run times and experience of handling and feeding the coal in winter conditions.

Based on the data developed through the testing of the Phase I unit, a Phase II system was designed for feeding coal into pressures of up to $35 \mathrm{~kg} / \mathrm{cm}^{2}(500 \mathrm{psi})$. A further program of testing and modification was then carried out in Stamet's facility, with the target pressure being achieved in January 2005. Repeated runs at pressure were achieved, and optimization of the machine resulted in power reductions of $60 \%$ from the first successful pressure runs.

General design layout of a commercial-scale 500psi unit was conducted, and preliminary cost estimates for a commercial unit obtained.

Based on the successful work done in Phases I \& II using Powder River Basin coal provided by the PSDF facility in Wilsonville, AL, a Phase III feeder system was designed and built to accomplish the target of feeding the coal into a pressure of $70 \mathrm{~kg} / \mathrm{cm}^{2}(1,000 \mathrm{psi})$ and to be capable of feed rates of up to 550 kilograms $(1,200 \mathrm{lbs})$ per hour when feeding into atmospheric 
pressure. The drive motor system from Phase II was retained for use on Phase III since projected performance calculations indicated it should be capable of driving the Phase III pump to the target levels. The pump \& motor system was installed in an upgraded test rig with all pressure containment on the rig rated to $105 \mathrm{~kg} / \mathrm{cm}^{2}(1,500 \mathrm{psi})$ to accommodate the final pressure requirement of a proposed Phase IV of the program. A screw conveyor and batch hopper were added to transfer coal at atmospheric pressure from the shop floor up into the test rig to enable continuous feeding up to the capacity of the receiving vessel. Control \& monitoring systems were up-rated from the Phase II system to cover the additional features incorporated in the Phase III rig, and provide closer control and expanded monitoring of the entire system.

A program of testing and modification was carried out in Stamet's facility in CA, culminating in the first successful feeding of coal into the Phase III target of $70 \mathrm{~kg} / \mathrm{cm}^{2}(1,000 \mathrm{psi})$ gas pressure in March 2007. Subsequently, repeated runs at pressure were achieved, and comparison of the data with Phase II results when adjusted for scale differences showed further power reductions of $40 \%$ had been achieved from the final Phase II pressure runs.

The general design layout of a commercial-scale 1,000psi unit was conducted, and preliminary cost estimates made.

During the work on Phase III an opportunity was identified to demonstrate a commercial scale feeder at the Power Systems Development Facility (PSDF) in Wilsonville Al. This would provide for extended run times to exceed $1,000 \mathrm{hrs}$ at pressures up to 550psi and flow rates up to 10tph. Phase V of the project was added in Oct. 2006 to achieve this commercial scale demonstration.

While design work was underway on the Phase $\mathrm{V}$ feeder and installation, and prior to the award of the proposed Phase IV of the project, the Stamet Posimetric ${ }^{\circledR}$ Feeder Technology was acquired by GE Energy LLC. No agreement to novate the contract was agreed with GE Energy, so the program was terminated as of June $11^{\text {th }} 2007$. This final report documents all work on the program through that date. 


\section{Table of Contents}

$\begin{array}{ll}\text { Disclaimer } & 2\end{array}$

$\begin{array}{ll}\text { Abstract } & 3\end{array}$

$\begin{array}{ll}\text { Introduction } & 6\end{array}$

$\begin{array}{ll}\text { Executive Summary } & 9\end{array}$

$\begin{array}{ll}\text { Experimental } & 11\end{array}$

$\begin{array}{ll}\text { Results and Discussion } & 20\end{array}$

$\begin{array}{ll}\text { Conclusions } & 40\end{array}$ 


\section{Introduction}

The overall goal of this project was to provide and confirm an alternative technological solution for solid fuel injection into proposed advanced combustion systems. Operators and designers of high-pressure combustion systems universally agree that one of the major problems inhibiting the success of this technology relates to solid materials handling at high pressures. Continuing problems feeding coal into high-pressure gas environments and the well-recognized complexity of existing handling systems has limited acceptance of advanced combustion and gasification technology. Limitations inherent in the batch process character of existing lock hopper and piston pump paste systems prevent controlled, continuous level delivery of the coal, imposing gas losses, high maintenance costs and substantial risks of downtime. This program is aimed at developing the Stamet Posimetric ${ }^{\circledR}$ High Pressure Solids Feeder to provide the simple, accurate and reliable feed system needed to maintain the lead of the U.S. in advanced combustion system design and supply.

The Posimetric ${ }^{\circledR}$ feeder has only one moving part, a rotating spool formed of two disks and a hub, which rotates within a stationary housing. Material entering the feeder becomes locked between the disks and is carried round as the spool rotates until it reaches the outlet port. This principle of lockup means the pump experiences virtually no wear. At the outlet a moving solids seal is continuously created, used as a seal and then dismantled as it is displaced by fresh material as the feeder operates into pressure. The solids pass through the feeder in a continuous unbroken stream, at a rate directly proportional to the speed of rotation.

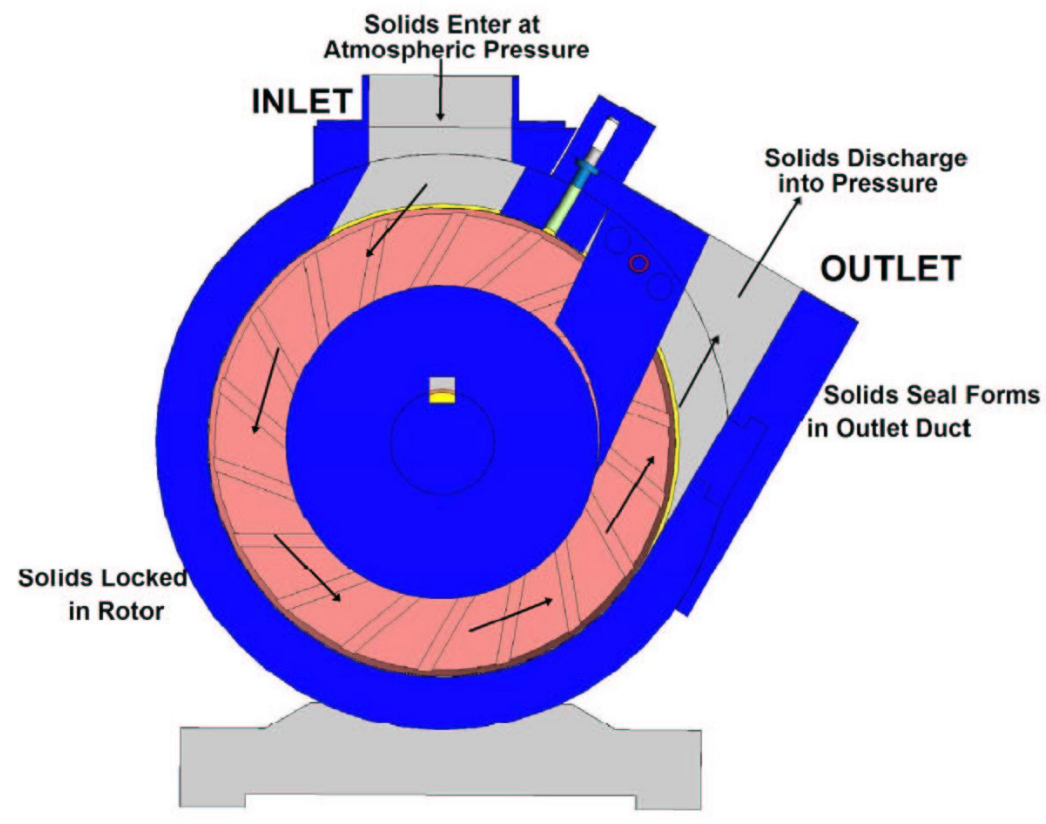

Fig. 1. Layout of Stamet Posimetric ${ }^{\circledR}$ Pressure Feeder 
Previous work under SBIR grants had demonstrated the ability of the Stamet Posimetric ${ }^{\circledR}$ High Pressure Solids Feeder to pump coal successfully into pressures as high as $11 \mathrm{~kg} / \mathrm{cm}^{2}$ (160 psi) and further development carried out by Stamet achieved successful pumping into $15 \mathrm{~kg} / \mathrm{cm}^{2}(210$ psi).

The overall objective of this project is the development of a mechanical rotary-disk feeder, known as the Stamet Posimetric ${ }^{\circledR}$ High Pressure Solids Feeder System, to demonstrate feeding of dry granular coal continuously and controllably into pressurized environments. The initial award was granted in 2 phases, demonstrating continuous feeding into 300psi and 500psi respectively. During the course of the project, driven by the higher projected operating pressures proposed for next generation coal gasification systems, a further 2 phases were added. Phase III to demonstrate continuous injection into 1,000psi was approved in July 2005, and, contingent on Phase III success, Phase IV was planned to reach the 1,300psi pressure level. The initial plan for the current project provided for two phases to extend this capability to achieve the objective of feeding into $35 \mathrm{~kg} / \mathrm{cm}^{2}$ (500 psi). Subsequently Phase III was added to achieve feeding into 1,000psi, and a Phase IV was planned to go to 1,300psi. During the work on Phase III an opportunity was identified to demonstrate a commercial scale feeder at the Power Systems Development Facility (PSDF) in Wilsonville Al. This would provide for extended run times to exceed $1,000 \mathrm{hrs}$ at pressures up to 550psi and flow rates up to 10tph. Phase V of the project was added in Oct. 2006 to achieve this commercial scale demonstration.

The objectives of each approved phase were as follows.

Phase I:

Evaluate and select suitable coal material specification for feeder testing to minimize material handling issues affecting the program while maintaining relevance to the requirements of existing high pressure combustion and gasification processes.

Design, manufacture and test a semi-scale, $21 \mathrm{~kg} / \mathrm{cm}^{2}$ (300 psi) pressure capable, machine and test rig.

Test and evaluate design concepts and elements for internal pump configuration including inlet and outlet arrangements to build confidence in design for higher pressures in phase 2.

Phase II:

Design, manufacture and testing of a modified feeder and test rig capable of discharging at the full operating pressure of $35 \mathrm{~kg} / \mathrm{cm}^{2}$ (500 psi).

Generate a general design and preliminary cost estimate for a commercial-scale feeder.

Phase III:

Confirm a suitable coal material specification for feeder testing which maintains relevance to the requirements of proposed high-pressure combustion and gasification processes and has feed characteristics compatible with the scale of the test feeders to be used in the program.

Test and evaluate design concepts and elements for internal pump configuration including inlet and outlet arrangements to build confidence in design for higher pressures.

Design, manufacture and testing of a feeder and test rig capable of discharging at the full operating pressure of $70 \mathrm{~kg} / \mathrm{cm}^{2}(1,000 \mathrm{psi})$

Evaluate a general design layout and estimated costing for a commercial-scale feeder. 
Phase V:

Confirm design specifications applicable to commercial feeder design and installation, including but not limited to safety standards, design codes for pressure containment and hazardous environmental considerations.

Design a large-scale feeder and ancillary equipment capable of continuous injection of pulverized coal into 550psi at a rate of 10tph for extended periods. Planned test duration $>1,000 \mathrm{hrs}$.

Manufacture and install the feeder and ancillaries at the PSDF facility.

Operate \& monitor performance off-line and on-line with an operating gasifier.

Report on testing and recommendations for commercial design improvements.

This final report documents the work done on the four phases of the project between October $15^{\text {th }}$ 2002 and June $11^{\text {th }} 2007$. 
DE-FC26-02NT41439

\section{$\underline{\text { Executive Summary }}$}

The overall objective of this project is the development of a mechanical rotary-disk feeder, known as the Stamet Posimetric ${ }^{\circledR}$ High Pressure Solids Feeder System, to feed dry granular coal continuously and controllably into pressurized environments for Pressurized Fluid Bed \& gasification applications. The Posimetric ${ }^{\circledR}$ feeder has only one moving part, a rotating spool formed of two disks and a hub, which rotates within a stationary housing. Material entering the feeder becomes locked between the disks and is carried round as the spool rotates until it reaches the outlet port. This principle of lockup means the pump experiences virtually no wear. At the outlet a moving solids seal is continuously created and then dismantled as it is displaced by fresh material as the feeder operates into pressure. The solids pass through the feeder in a continuous unbroken stream, at a rate directly proportional to the speed of rotation. The development program was divided into a number of phases as follows:

\section{Phase I: Demonstrate Injection into 300psi}

The first task was to review materials handling experience in pressurized operations and review existing coal preparation processes and specifications currently used in advanced combustion systems. Samples of existing fuel materials were obtained and tested to provide input data for use in the design of the Stamet Feeders for the project, and ensure that the material specification used met the requirements of advanced combustion \& gasification systems. Ultimately, PRB coal prepared by the PSDF facility in Wilsonville, AL was used for the test program.

A Phase 1 feeder system was designed and built to accomplish feeding the coal into pressures up to $21 \mathrm{~kg} / \mathrm{cm}^{2}$ (300 psi) at feed rates of approximately 100 kilograms (220lbs) per hour. The pump was designed and built as small as possible consistent with retaining inlet flow capability to minimize the cost of the initial machine and subsequent modifications. The pump \& motor system was installed in a custom built test rig comprising an inlet vessel containing an active live-wall hopper mounted in a support frame, a transition into the pump inlet, a transition from pump outlet and a receiver vessel containing a receiver drum supported on weigh cells. All pressure containment on the rig was rated for the final pressure requirement of $35 \mathrm{~kg} / \mathrm{cm}^{2}$ (500psi). The inlet hopper of the pump was contained in a pressure vessel so that during testing to investigate any failure modes, the material and gas would be contained within the rig. The system was fully instrumented and controlled from a PC using custom LabVIEW programming.

A program of testing and modification was carried out in Stamet's facility in CA, feeding coal into progressively increasing pressure, culminating in successful feeding of coal into the Phase 1 target of $21 \mathrm{~kg} / \mathrm{cm}^{2}$ (300psi) gas pressure in December 2003. Following this the complete rig was shipped to Homer City, PA where further testing was carried out at CQ Inc's facility, providing for longer run times and giving experience handling and feeding the coal in winter conditions.

Phase II: Demonstrate Injection into 500psi

Based on the Phase I data a Phase II system was designed for feeding coal into pressures of up to $35 \mathrm{~kg} / \mathrm{cm}^{2}$ (500 psi). A further program of testing and modification was then carried out in 
Stamet's facility, with the target pressure being achieved in January 2005. Repeated runs at pressure were achieved, and further optimization of the machine design resulted in power reductions of $60 \%$ from the first successful pressure runs.

A design and preliminary cost estimate for a commercial-scale 500psi feeder was generated.

\section{Phase III: Demonstrate Injection into 1,000psi}

To supplement the data from the Powder River Basin coal, some preliminary testing was done with lignite and some biomass mix fuels, and overall results were used as the basis for the feeder design and test program.

A Phase III feeder system was designed and built to accomplish feeding the coal into pressures up to $70 \mathrm{~kg} / \mathrm{cm}^{2}(1,000 \mathrm{psi})$ at feed rates up to 550 kilograms $(1,200 \mathrm{lbs})$ per hour. The pump \& motor system was installed in an upgraded test rig with all pressure containment on the rig rated to $105 \mathrm{~kg} / \mathrm{cm}^{2}(1,500 \mathrm{psi})$ to accommodate the final pressure requirement of a proposed Phase IV of the program. A screw conveyor and batch hopper were added to transfer coal at atmospheric pressure from the shop floor up into the test rig to enable continuous feeding up to the capacity of the receiving vessel. Control \& monitoring systems were up-rated from the Phase II system to cover the additional features incorporated in the Phase III rig, and provide closer control and expanded monitoring of the entire system.

A program of successive testing and modification was carried out in Stamet's facility in CA, feeding coal into progressively increasing pressure, culminating in successful feeding of coal into the Phase III target of $70 \mathrm{~kg} / \mathrm{cm}^{2}$ (1,000 psi) gas pressure in March 2007. Repeated runs at pressure were achieved, and comparison of the data with Phase II results, when adjusted for scale differences, showed further power reductions of $40 \%$ had been achieved from the final Phase II pressure runs.

This demonstrated the feasibility of using the Stamet Posimetric ${ }^{\circledR}$ High Pressure Solids Feeder System up to the target 1,000psig pressure level, and provided data on power and sizing requirements to be projected for commercial applications. The general design layout of a commercial-scale unit was conducted, and preliminary cost estimates for manufacture of a commercial scale unit made.

Phase IV: Demonstrate Injection into 1,300psi - not implemented.

Phase V: Large Scale Commercial Demonstration at pressures up to 550psi

Design work was carried out for a commercial scale pump and ancillaries capable of feeding 10 tph into 550psi for extended time periods. Installation issues at PSDF were addressed and manufacturing considerations were underway when, on June $11^{\text {th }}$ 2007, GE Energy LLC acquired the Stamet Posimetric ${ }^{\circledR}$ Pump technology and work on the program was suspended.

No agreement was reached to novate the contract so the project was closed. This final report documents all activities and achievements through that date. 


\section{Experimental.}

\section{Material Evaluations:}

The project commenced with review of current equipment and operating specifications of pressurized combustion and gasification systems and identification of feed material properties desirable for achieving the target pressures. Additionally, coal preparation processes were reviewed to develop a proposed material specification that ensured final feed material specifications were consistent with coal preparation plant capabilities and advanced combustion systems being fed. Samples were obtained from users for evaluation.

Samples were subjected to a sieve analysis and moisture measurement. They were additionally evaluated for properties that would be important to the operation of the pump including flowability, bulk density, compressibility, friction and permeability.

Inlet flow characteristics were evaluated by measuring flowrates through a series of hoppers with different sized exits. Hoppers were filled via a small conveyor to ensure consistent fill rates, and then the outlet was opened and the time for the hopper to empty measured (Figures $2 \mathrm{a} \& 2 \mathrm{~b}$ ).

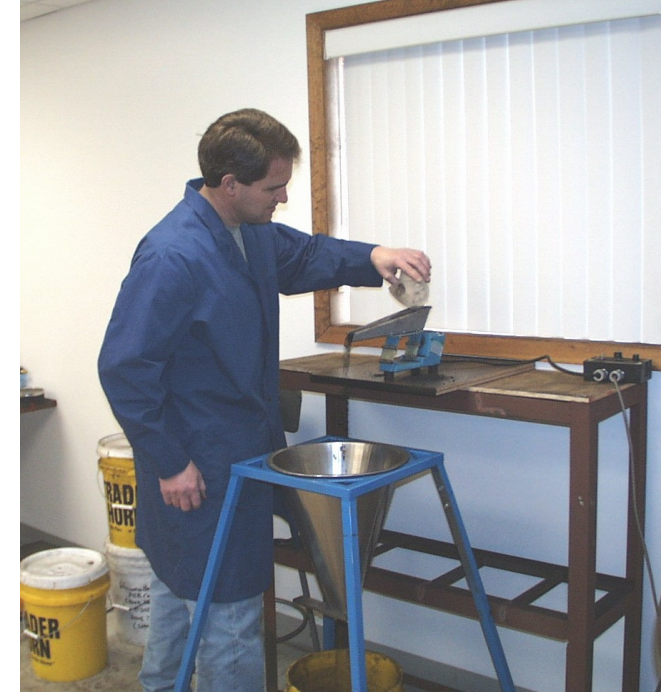

Fig.2a Filling Test Hopper

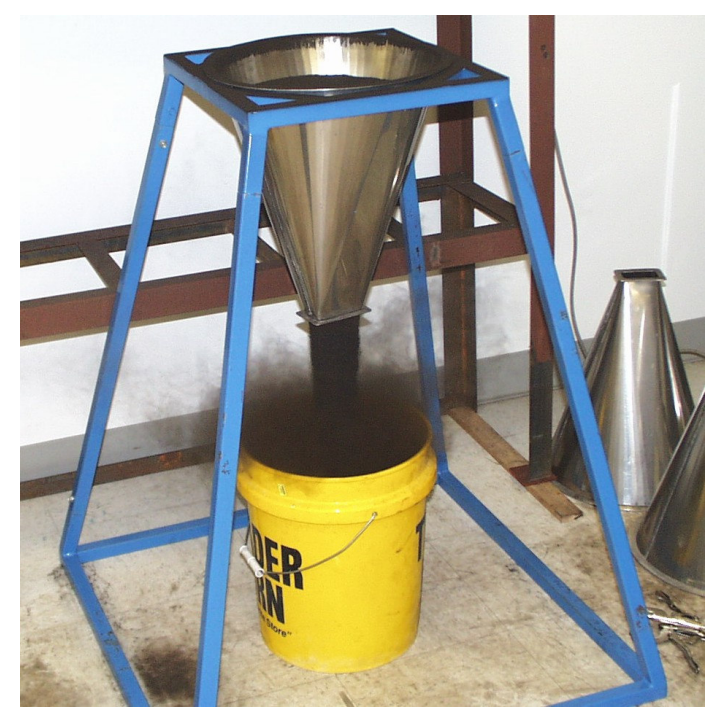

Fig.2b Emptying Test Hopper.

Bulk density, compressibility friction and permeability were evaluated using a custom designed

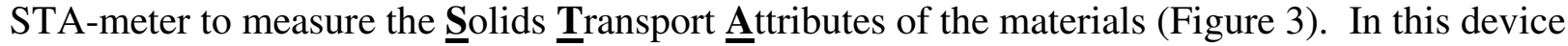
a known weight of material is added into a tube to provide a column of material. Gas pressure can be applied to the top of the column, which can then be driven up the tube by a piston from below. Measurements of column length, friction force, pressure and gas leakage rates allow density, compressibility, friction and permeability of different samples to be evaluated. 
DE-FC26-02NT41439

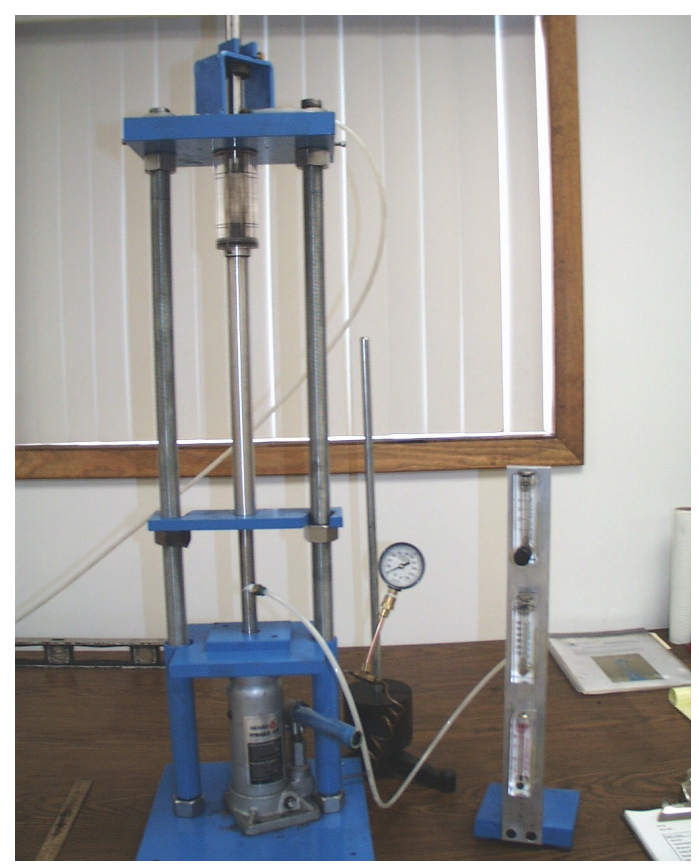

Fig.3 STA-meter

\section{Test Pump - Phases I \& II:}

The research program was designed to minimize the cost to achieve the target pressure level. Rather than building two complete machines for phase I \& II, the phase I unit was designed to allow it to be modified to meet the Phase II requirements.

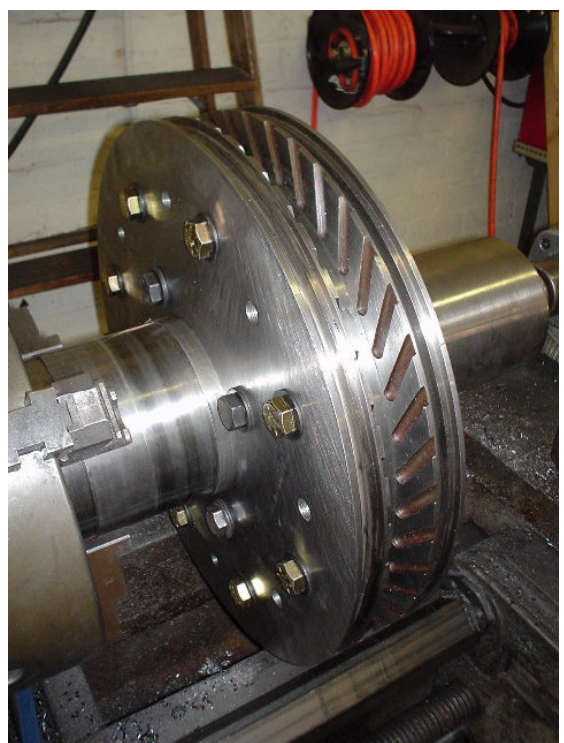

Fig.4 Spool Assembly

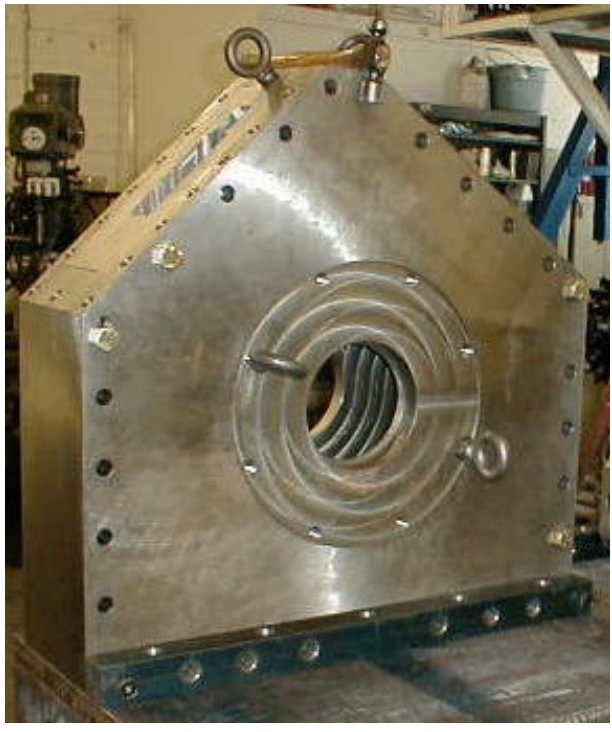

Fig.5 Pump Body

As with all Posimetric ${ }^{\circledR}$ feeders, the research pump has only one moving part - the spool (Figure 4), comprising two discs and a hub spacer on a shaft. The spool rotates inside the body housing (Figure 5). Unique to this body design was the use of inserts for inlet and outlet components 
(Figure 6). These allow the inlet and outlet configurations to be readily changed without requiring major modifications to the pump body.

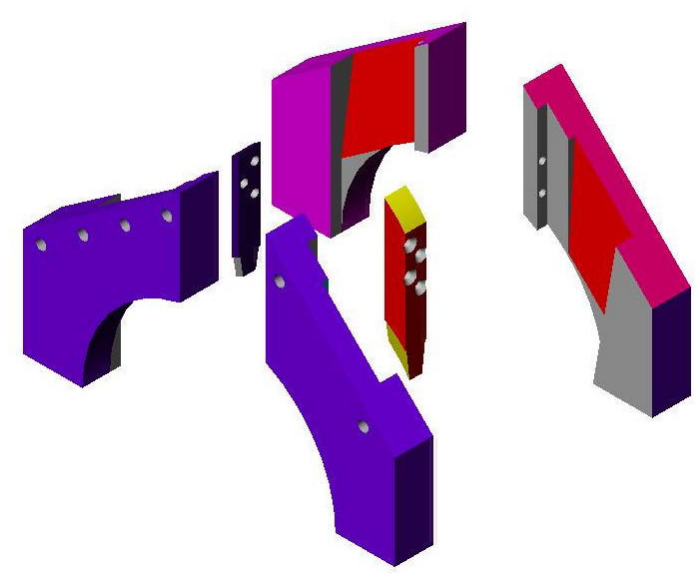

Fig. 6 Inlet \& Outlet Inserts

\section{Pump Test Rig - Phases I \& II:}

The pump was mounted on a platform and coupled to an electric motor/gearbox unit via a drive chain. The electric motor was powered via a variable frequency drive to provide speed control from 0 to $5 \mathrm{rpm}$.

The pump \& motor system was installed in a custom built test rig comprising an inlet vessel containing an active live-wall hopper mounted in a support frame, a transition into the pump inlet, a transition from pump outlet and a receiver vessel containing a receiver drum supported on weigh cells (Figure 7).

The rig was instrumented to monitor pressures throughout the system, material presence and flowrates, gas flowrates, speed and drive torque. The system was controlled from a PC using custom LabVIEW programming which also recorded the sensor data in real time. Video recordings were also made during testing showing the outlet feed condition, inlet flow and data capture screen (Figure 8). 
DE-FC26-02NT41439

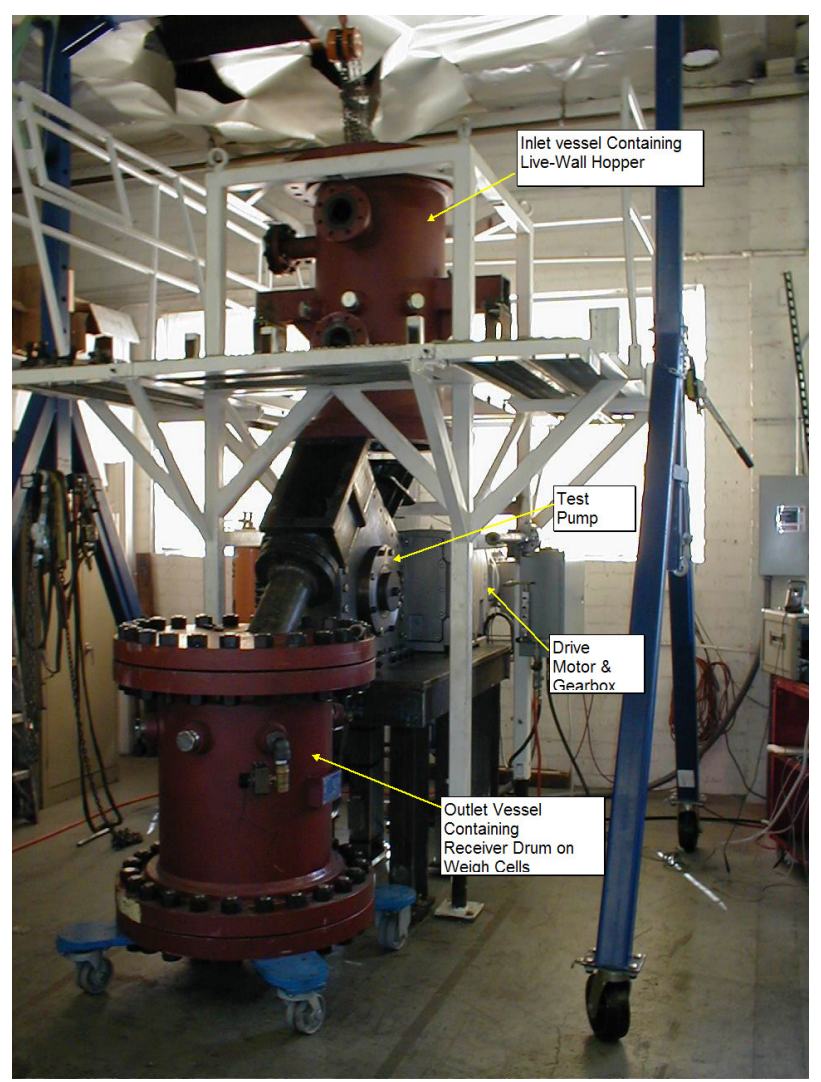

Fig.7 Pump Test Rig

All pressure containment on the rig was rated for the final pressure requirement of $35 \mathrm{~kg} / \mathrm{cm}^{2}$ (500psi). The inlet hopper of the pump was contained in a pressure vessel so that during testing to investigate any failure modes the material and gas could be contained within the rig. The system was fully instrumented and controlled from a PC using LabVIEW programming.

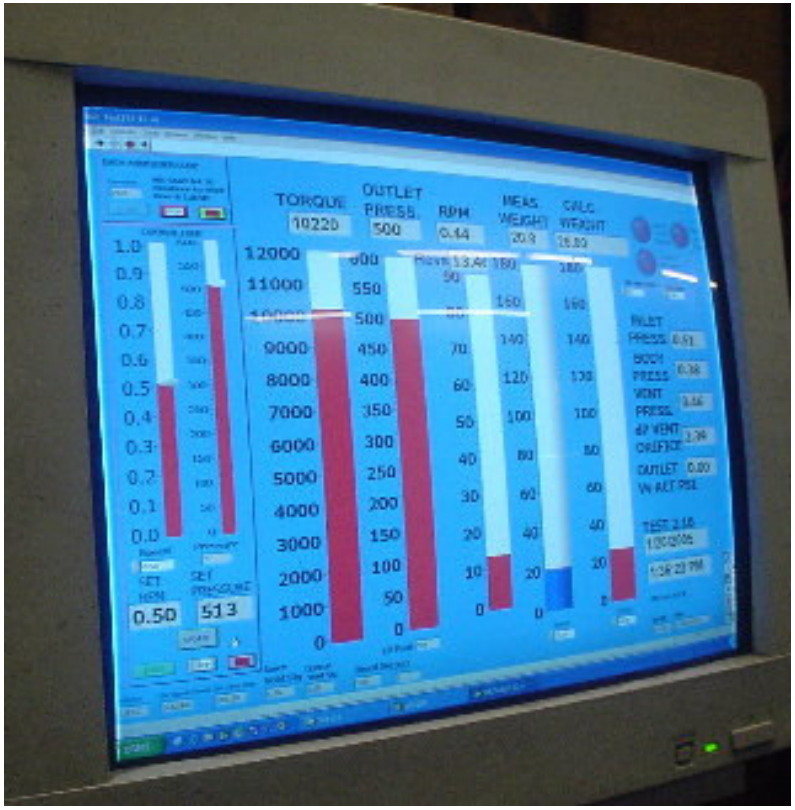

Fig.8 Dataq \& Control Screen 


\section{Test Pump - Phase III:}

Whilst the Phase I/II pump was designed to minimize the cost to achieve the target pressure level, for Phase III the pump design was sized to provide a scale-up of approx 5:1 on volumetric capacity from the requirements of Phase II, while still being small enough to allow testing in Stamet's facility and reasonable costs of development modifications. Also, the machine design configuration was closer to that of a commercial system, rather than utilizing the large replaceable inlet \& outlet inserts that had been used to provide maximum flexibility of pump configurations for Phases I \& II. The pump used separate end caps with outboard bearings to provide full separation from any material that may enter the pump body cavity. As with all Posimetric ${ }^{\circledR}$ feeders, the research pump has only one moving part - the spool which rotates inside the body housing to transport material from the inlet to the outlet. A replaceable outlet insert was still incorporated in the design, as it is anticipated that this would be the case for a commercial unit where service replacement components would be provided.

Fig. 9 shows the general arrangement of the pump.

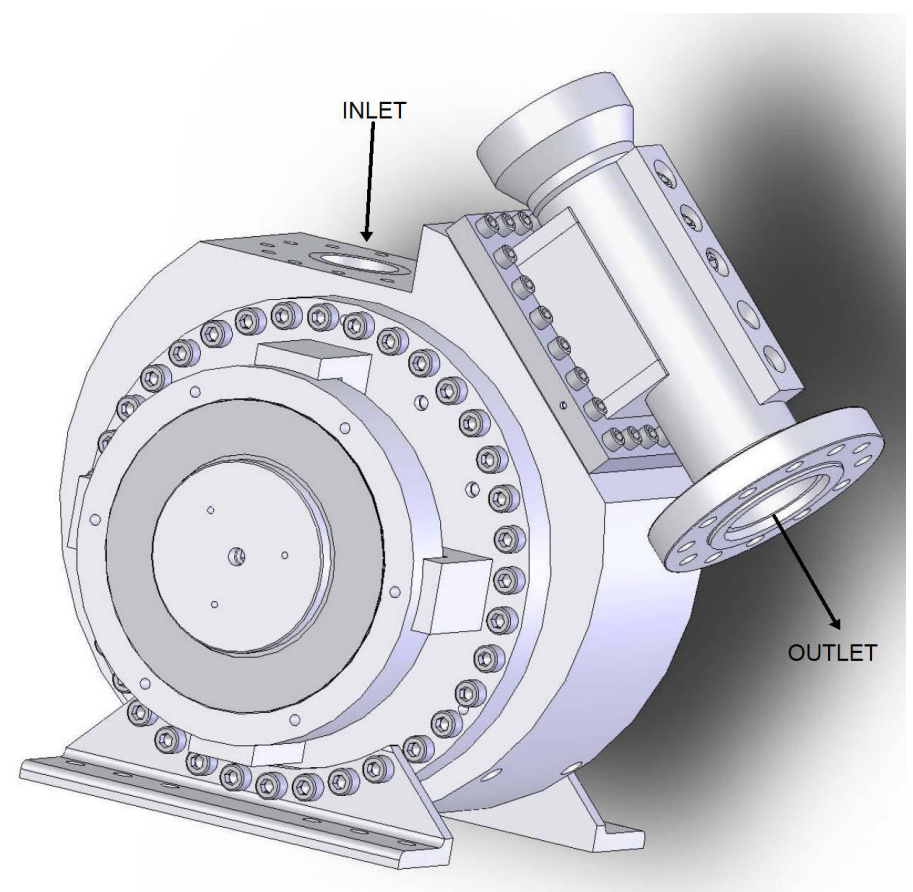

Fig. 9 Pump General Arrangement 


\section{Pump Test Rig - Phase III:}

The pump was mounted on a platform and coupled to an electric motor/gearbox unit via a drive chain. The motor/gearbox unit was mounted on the underside of the platform to provide a compact installation and was powered via a variable frequency drive to provide speed control from 0 to $5 \mathrm{rpm}$. This arrangement is shown in Fig. 10.

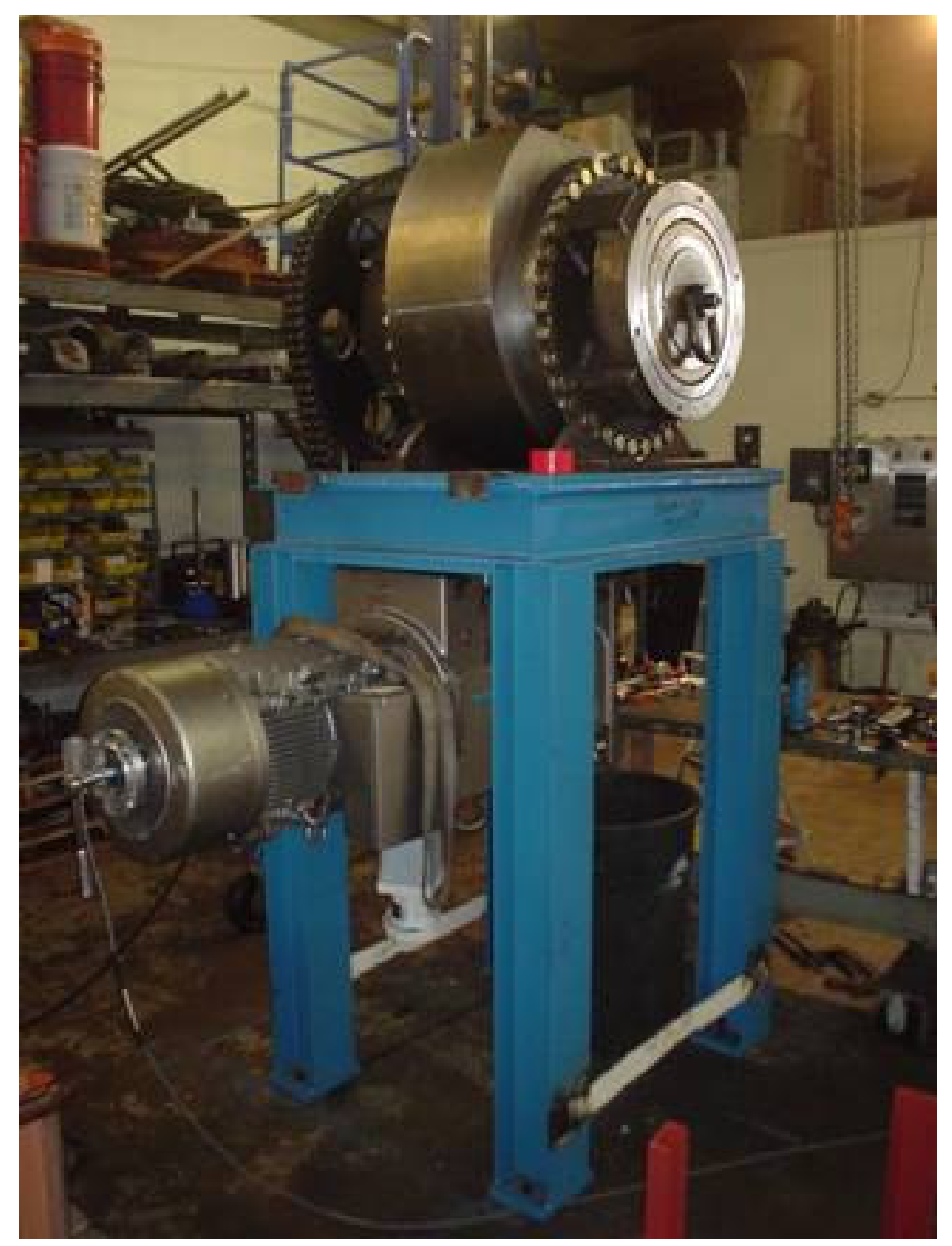

Fig. 10. Pump and Drive Arrangement

The pump \& motor system was installed in a custom built test rig comprising an inlet vessel containing an active live-wall hopper mounted on load cells, the pump itself, a transition from pump outlet and a receiver vessel containing a receiver drum supported on weigh cells. The pump platform was designed to position the motor as high as possible, allowing space for the height of the equipment to be mounted above, so that the size of the receiver vessel could be maximized. Low profile actuated isolation valves were provided on the entry to the inlet vessel and between the outlet transition and receiver vessel. All pressure containment on the rig was rated at $105 \mathrm{~kg} / \mathrm{cm}^{2}(1,500 \mathrm{psi})$ to accommodate the final pressure requirement of the proposed 
future Phase IV of the program. A floor mounted hopper supplying a screw conveyor feeding a supply hopper above the inlet vessel, also mounted on load cells, were added to transfer coal at atmospheric pressure from the shop floor up into the test rig. This enabled continuous feeding up to the capacity of the receiving vessel. Fig. 11 shows the test rig arrangement in the solid modeler and Fig.12 shows a picture of the actual system as installed.

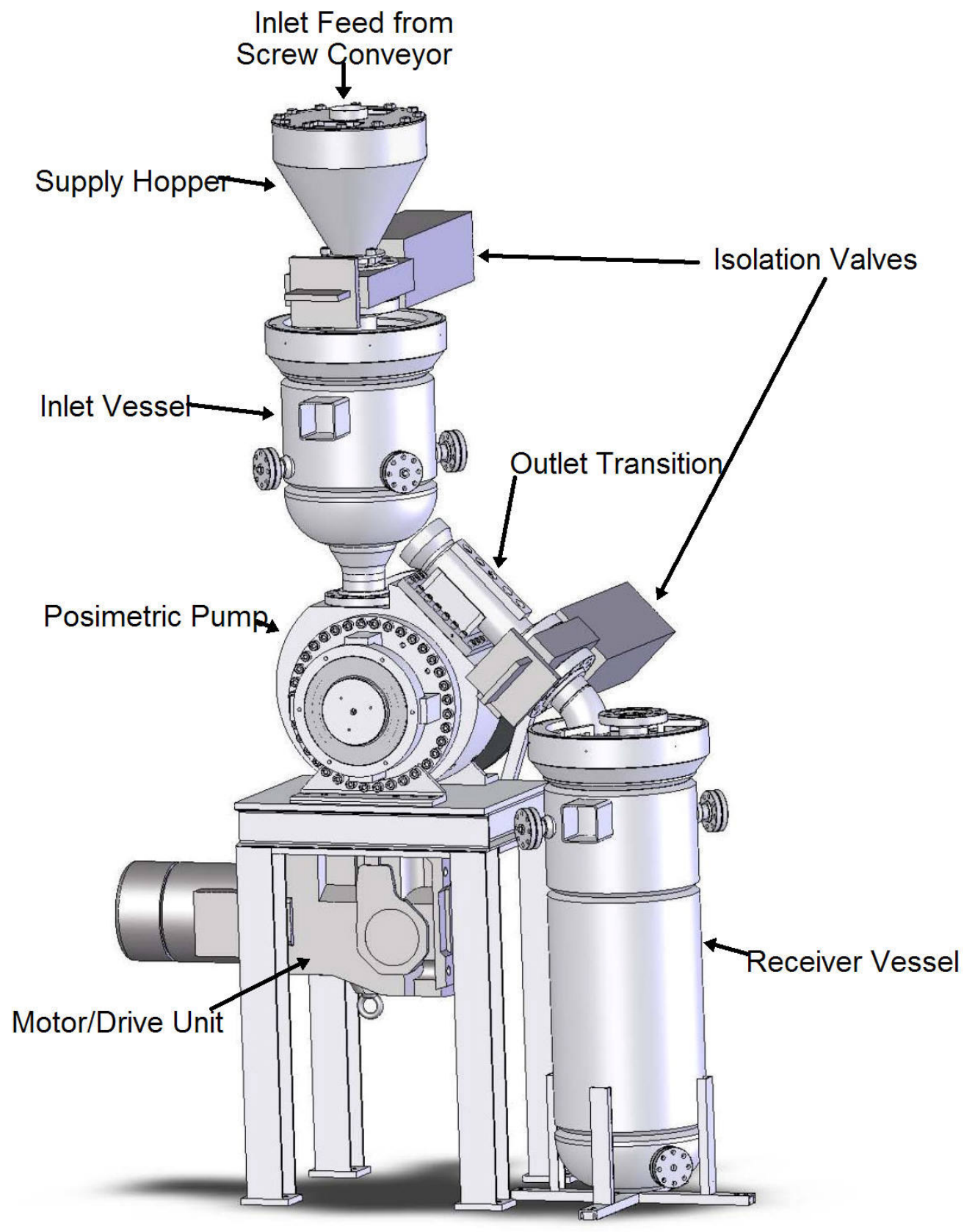

Fig. 11 Test Rig Arrangement 


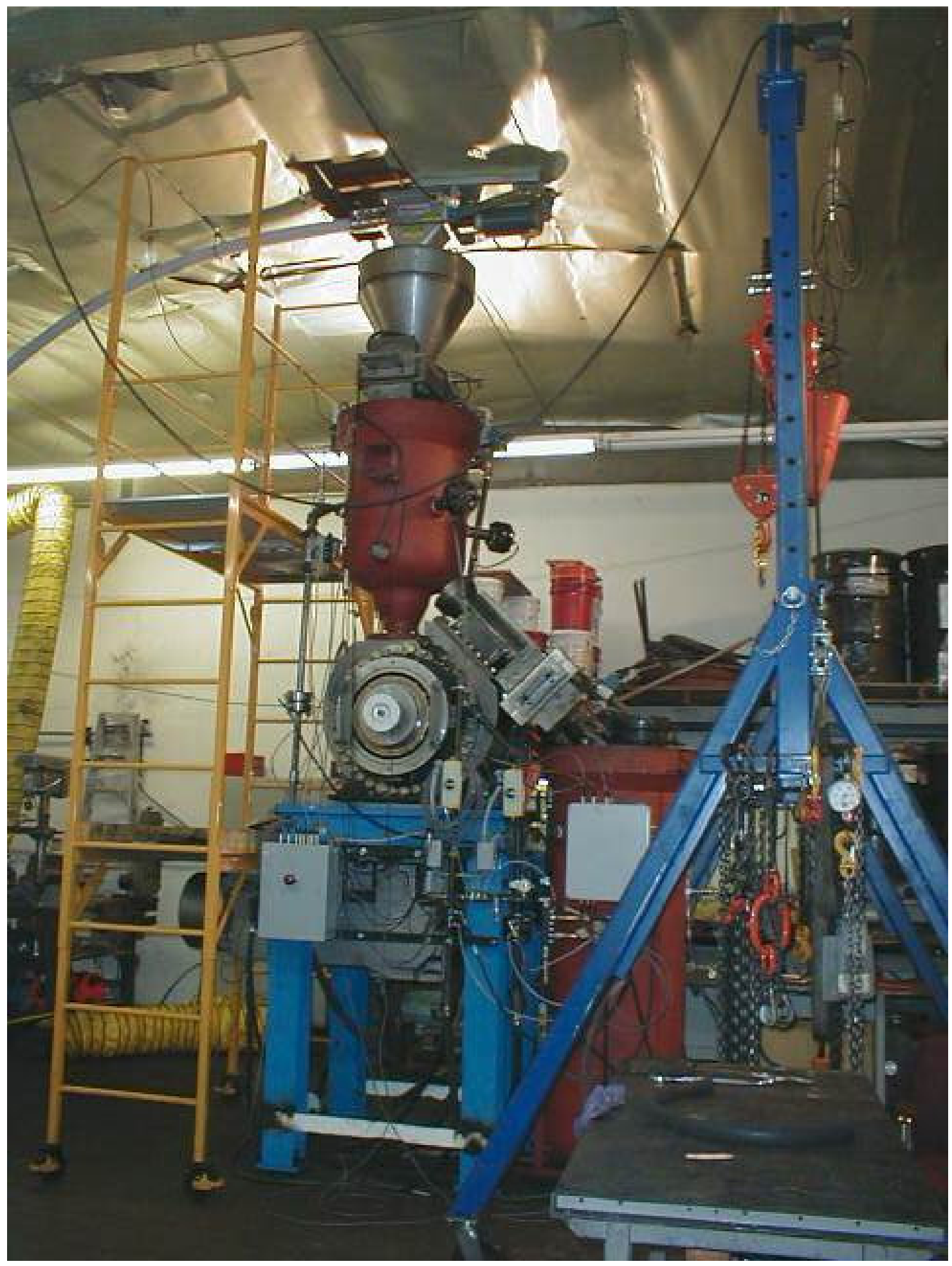

Fig. 12 Actual Test Rig Installation 
The rig was instrumented to monitor pressures throughout the system, material presence and flow-rates, gas flow-rates, speed, and drive torque. The system was controlled from a PC using custom LabVIEW programming, which also recorded and graphed the sensor data in real time (Figures 13 \& 14). Mpeg \& Video recordings were also made during testing to capture the outlet feed condition, inlet flow and system control screen.

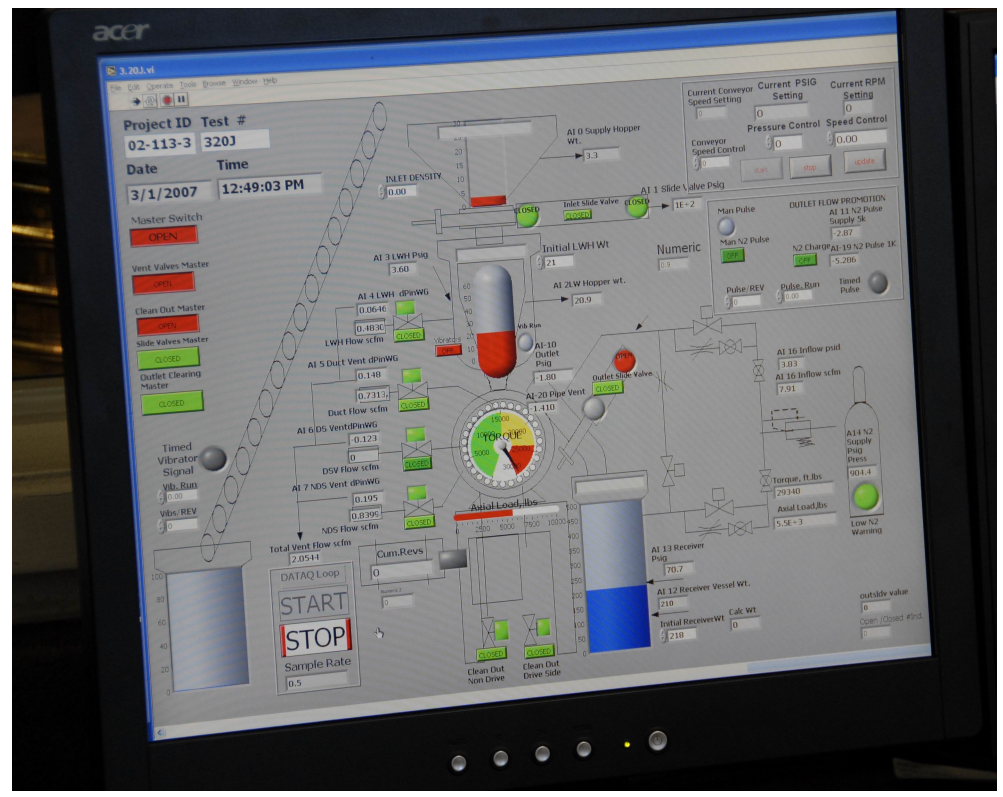

Fig.13 Primary Dataq \& Control Screen

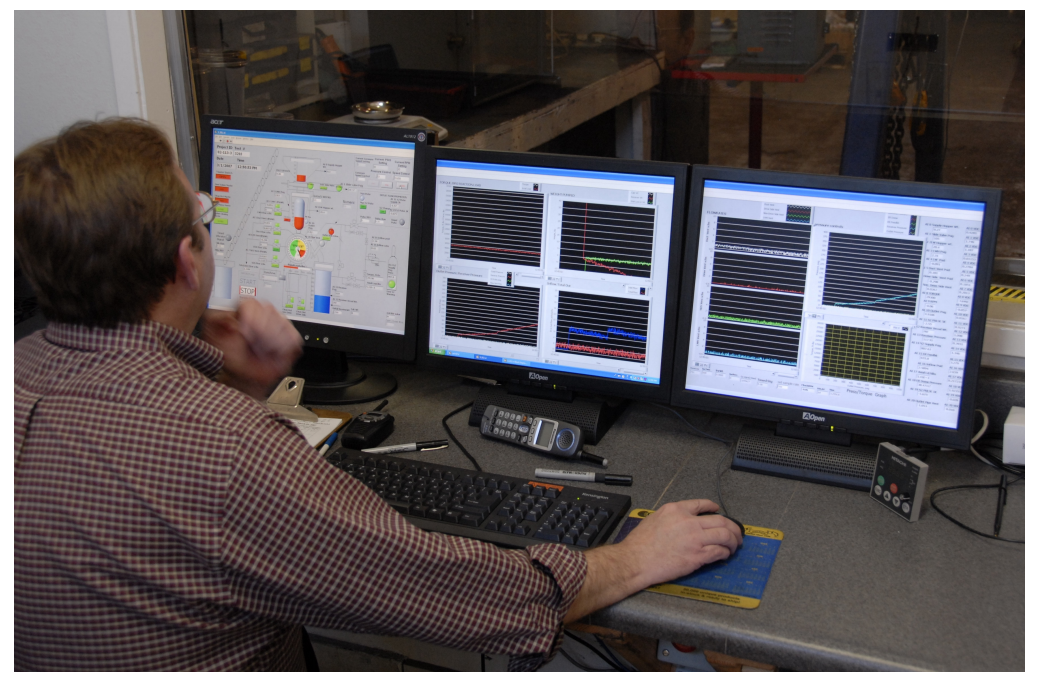

Fig. 14 Multiple Screens Tracking Test Rig Operation 
DE-FC26-02NT41439

\section{Results and Discussion.}

\section{Material Evaluations:}

Samples of existing fuel materials were obtained and tested to evaluate flow, sealing and friction properties. This provided input data for use in the design of the Stamet Feeders for the project, and ensured that the material specification used met the requirements of advanced combustion $\&$ gasification systems. Typical data obtained is shown below.

\begin{tabular}{|c|c|c|c|c|c|c|}
\hline \multirow{2}{*}{$\begin{array}{l}\text { DATE } \\
\text { RUN NO. }\end{array}$} & \multicolumn{4}{|c|}{ STAMET HOPPER TESTING } & & \\
\hline & \multicolumn{4}{|c|}{$\begin{array}{l}\text { 2/26/2003 } \\
03022601\end{array}$} & \multicolumn{2}{|r|}{ STA-METER TESTING } \\
\hline Type/Topsize & \multicolumn{4}{|c|}{ Sub-Bituminous Coal, Very Fine } & \multicolumn{2}{|l|}{ TEST COAL } \\
\hline Moisture $(\mathrm{Wt} \%)$ & \multicolumn{4}{|c|}{$\mathrm{TBD}(\sim 26-30)$} & \multirow{5}{*}{$\begin{array}{l}\text { Source } \\
\text { Type/Topsize } \\
\text { Moisture } \\
\text { Initial Wgt. } \\
\text { Remaining Wgt. } \\
\text { Sample Wgt. }\end{array}$} & \\
\hline HOPPER: & A & B & c & $\mathrm{D}$ & & As-received (8M topsize) \\
\hline Discharge $(\mathrm{mm} \times \mathrm{mm})$ & $76 \times 38$ & $65 \times 32.5$ & $52 \times 26$ & $40 \times 20$ & & 21.08 \\
\hline \multirow{7}{*}{\begin{tabular}{|l} 
Time to Empty (secs) \\
Observations \\
\end{tabular}} & \multirow{7}{*}{ 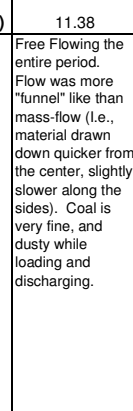 } & \multirow[t]{7}{*}{$\frac{16.78}{\text { Same }}$} & \multirow[t]{7}{*}{$\frac{28.73}{\text { Same }}$} & \multirow[t]{7}{*}{ Same } & & 230.9 \\
\hline & & & & & & 198.3 \\
\hline & & & & & TEST MEASUREMEN & grams \\
\hline & & & & & \multirow{5}{*}{$\begin{array}{l}\text { Initial Column Hgt. } \\
\text { Final Column Hgt. } \\
\text { Initial Leakage } \\
\text { Final Leakage } \\
\text { Hydraulic Pressure }\end{array}$} & \multirow[b]{5}{*}{$(\max )$} \\
\hline & & & & & & \\
\hline & & & & & & \\
\hline & & & & & & \\
\hline Coal Weight (grams): & $\underline{9,815}$ & $\underline{9,815}$ & $\underline{9,815}$ & $\underline{9,815}$ & & \\
\hline Flowrate, gm/s & 862.4780316 & 584.9225268 & 341.6289593 & 175.8960573 & \multirow{7}{*}{\multicolumn{2}{|c|}{$\begin{array}{l}\text { OBSERVATIONS } \\
\text { Hydraulic pressure varied with stroke, typically in 110-140 psi range. Max pressure } \\
\text { was } 140 \text { psi. After test, most of the material was easliy poured out from top of } \\
\text { sample tube with only light tapping; the remainder poured out from the bottom as } \\
\text { the push rod was withdrawn. }\end{array}$}} \\
\hline Flowrate, Ib/s & 1.901438906 & 1.289533656 & 0.753163061 & 0.387784494 & & \\
\hline $\begin{array}{l}\text { Density, lb/cu.ft } \\
\text { Flowrate cuts/s }\end{array}$ & $\begin{array}{r}45 \\
0.042254198\end{array}$ & $\begin{array}{r}45 \\
0.028656303\end{array}$ & $\begin{array}{r}45 \\
0.016736957\end{array}$ & $\begin{array}{r}45 \\
0\end{array}$ & & \\
\hline $\begin{array}{l}\text { Flowrate, culftis } \\
\text { Flow Area, sq.mm }\end{array}$ & $\begin{array}{r}0.042254198 \\
2888\end{array}$ & $\begin{array}{r}0.028656303 \\
2112.5\end{array}$ & $\begin{array}{r}0.016 / 3695 / \\
1352\end{array}$ & $\begin{array}{r}0.00861 / 433 \\
800\end{array}$ & & \\
\hline Flow Area, sq.ft & 0.031086173 & 0.022738761 & 0.014552807 & 0.008611128 & & \\
\hline Velocity, $\mathrm{tt} / \mathrm{s}$ & 1.359260193 & 1.260240335 & 1.150084451 & 1.000732176 & & \\
\hline & 81.55561159 & 75.61442008 & 69.00506705 & 60.04393054 & & \\
\hline
\end{tabular}

Fig.15 Material Test Data

Analysis of the data collected showed the Wilsonville PRB samples to provide excellent input flow properties, so that reliable inlet flow would be obtained. The friction loads were somewhat higher than other samples, but there was little variation in sealing capability. Discussions with site personnel visited had indicated that future requirements of their processes may lead to somewhat finer material being used, but little other modifications to the material specifications. Testing indicated that this would only lead to a reduction in venting requirements for the Stamet feeder which would be accommodated by designing for higher flow. The decision was made to proceed using the determined properties of the coal provided by Wilsonville PSDF as the basis for the feeder design, resulting in a feeder designed to handle the higher friction and flow requirements tested, so providing some flexibility in future fuel specifications, and allowing the use of a commercially available fuel for the project. 
DE-FC26-02NT41439

\section{Phase 1 Testing:}

The original pump configuration had been selected to maximize the drive capability by maximizing the angle between inlet and outlet to create the longest effective length of the duct, and minimize the resistance to flow by providing clear inlet and outlet paths. Initial checks were first carried out to confirm the basic functionality of the pump mechanicals and operation of the control and data acquisition systems. All systems operated successfully and initial data was obtained on the basic torque characteristics of the pump as originally configured, both empty and feeding coal into atmospheric pressure at a range of speeds.

The inlet flow system incorporated a patented live wall hopper system, which was actuated by void sensors at the pump inlet. Visual observations in the inlet when feeding the Wilsonville coal showed a tendency for the coal to rat-hole at the front side of the hopper, but once a void reached the sensors the vibrators actuated briefly and the rat-hole collapsed. Due to the ratholing tendency of the coal being used the control system was subsequently modified to include the option of a timed actuation of the vibrators to help ensure consistent inlet flow, which is critical to the correct operation of the system.

With the original, strongly diverging outlet configuration of the pump very little additional resistance was observed when feeding Wilsonville coal into atmospheric conditions. The torque levels increased due to the coal friction on the glide and through the outlet, and showed a similar dependency on speed, but the difference was only about $70 \mathrm{Nm}$ (50 ft.lbs.) To confirm adequate duct filling and drive in the pump, a mechanical load was then applied using an air-spring loaded plate to resist the coal flow at the pump exit.

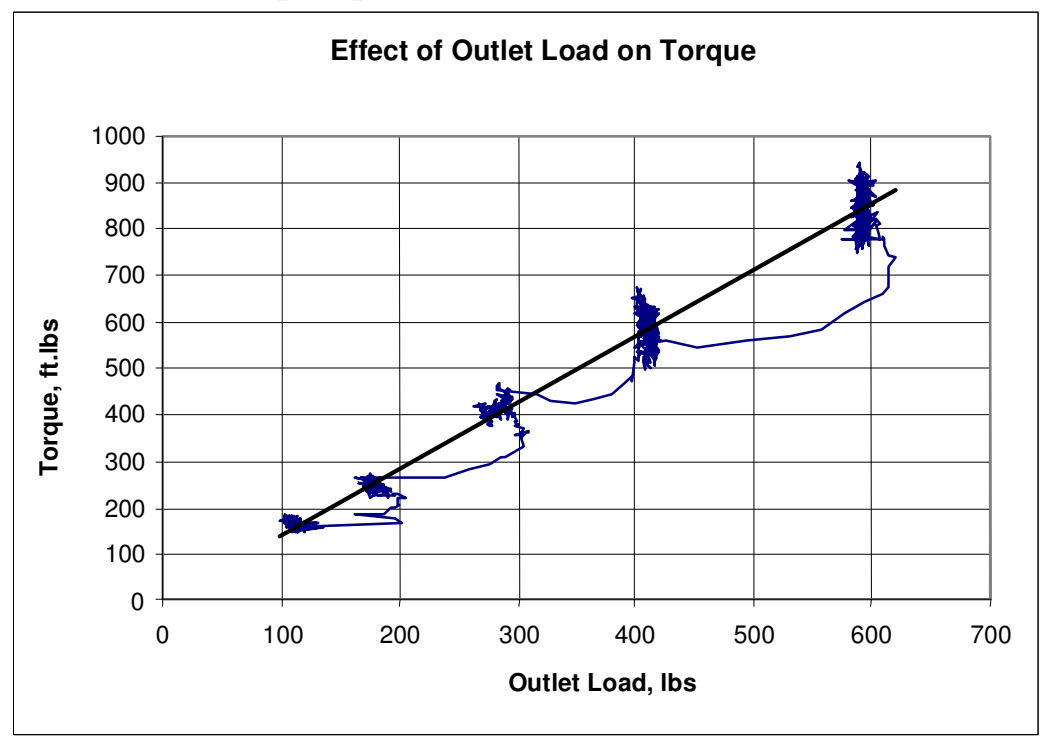

Fig.16 Relationship of Torque vs Outlet Load

Fig.16 shows typical data obtained, showing a linear increase in drive torque as outlet load was applied, indicating that a good grip was being obtained on the material in the pump duct. Steady outlet flow was obtained over the course of the tests confirming the ability to drive material in a controlled manner against a resistance. 
DE-FC26-02NT41439

Initial trials were then carried out feeding the Wilsonville coal into gas pressure, and Fig. 17 shows typical results obtained from the original configuration.

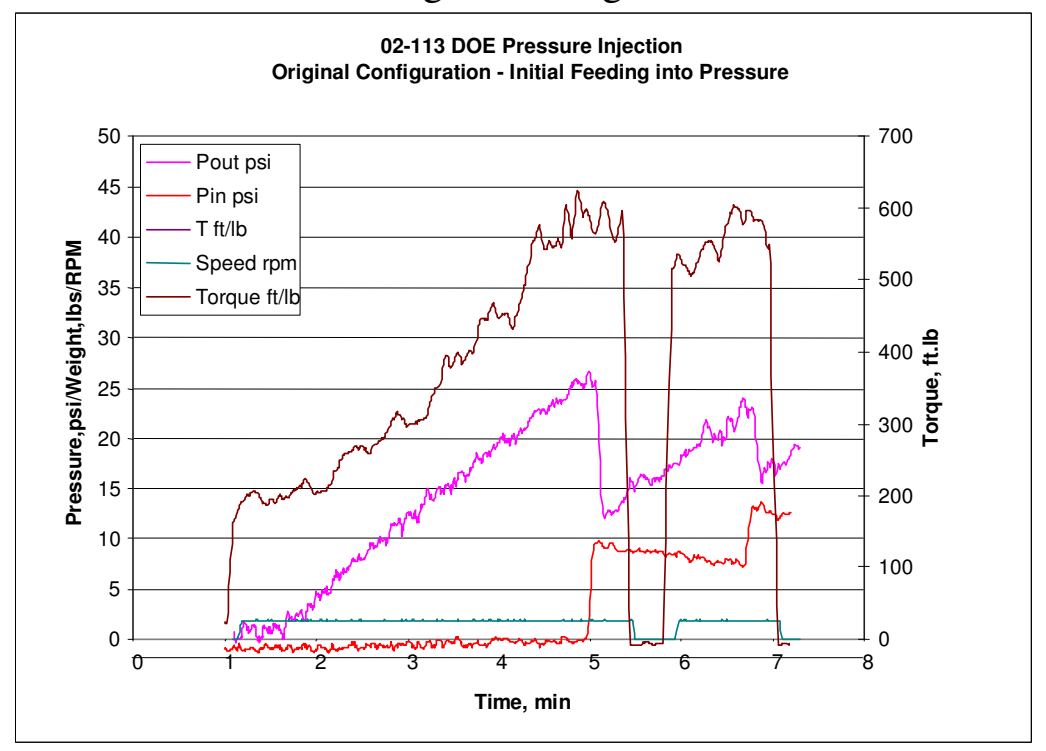

Fig.17 Original Gas Testing Data

As gas pressure is applied to the outlet of the running pump the drive torque increases with it. However, in this case at $1.75 \mathrm{~kg} / \mathrm{cm}^{2}$ (25psi) outlet pressure the outlet seal is suddenly lost and the gas pressure drops. When the pump is stopped and restarted the same thing recurs. With this outlet configuration a stable seal was not obtained with the Wilsonville coal, and eventually a rat-hole occurred in the outlet allowing gas to flow back through the pump. Changes to the outlet geometry were needed to establish a stable seal and allow reliable operation at higher outlet pressures.

The outlet inserts were modified to provide a much greater resistance to the outlet flow of material in order to establish a consolidated, stable material seal in the outlet. At the same time changes were incorporated to address issues with the disk sealing system, which had shown some binding and distortion during the course of the testing. This arrangement resulted in a stable outlet plug but required excessive torque when outlet pressure was applied.. Subsequent changes were made to the outlet inserts to progressively reduce the restrictions to flow so that a balance could be obtained where sufficient resistance was applied to produce a stable gas seal without exceeding the drive capability of the system.

After several iterations a balanced geometry was reached which provided a stable outlet gas seal without locking the rotor at full load. With this geometry the first run to feed coal into $21 \mathrm{~kg} / \mathrm{cm}^{2}$ (300 psi) was made in late December 2003. Data from this run is shown in Fig.18. 
DE-FC26-02NT41439

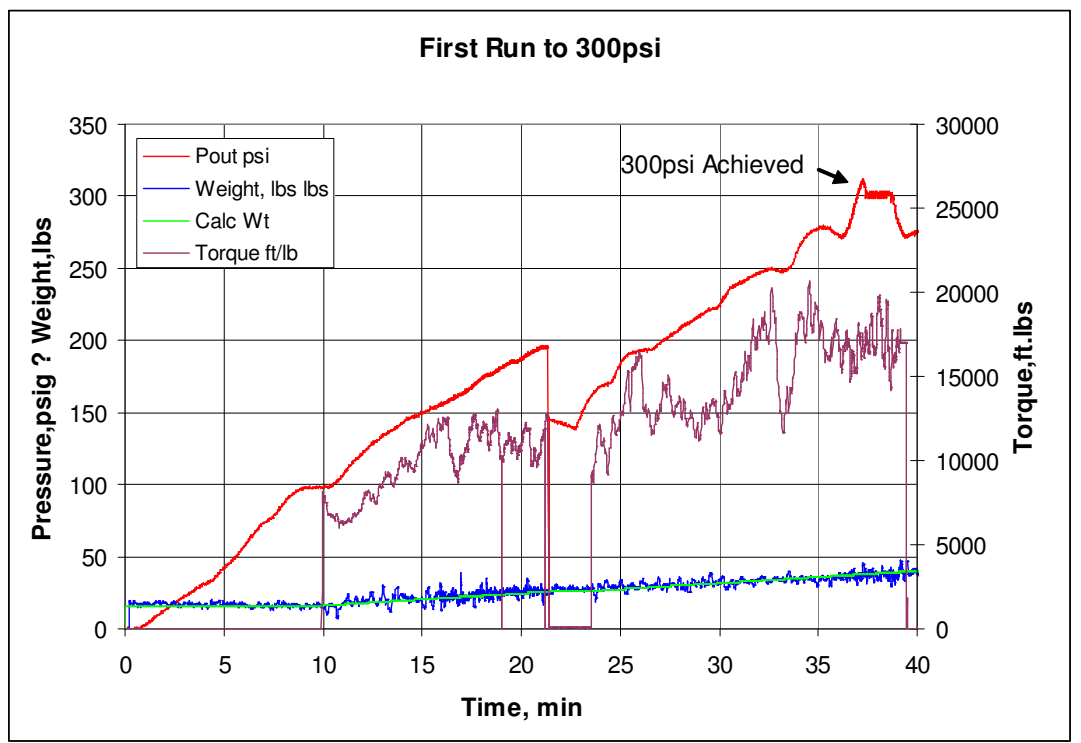

Fig.18 First Successful Run to $21 \mathrm{~kg} / \mathrm{cm}^{2}$ (300psi).

This outlet geometry still resulted in considerable resistance to the flow, requiring substantial torque to drive the material into the outlet containment. However, despite the high torque requirement the weight pumped was in good agreement with the calculated value, confirming that as long as the pump inlet is kept consistently filled with material the throughput remains directly proportional to rotational speed.

Fig.19 shows the relationship between the torque requirement and the outlet pressure. Although there are fluctuations due to variations in the material, the trend-line on the graph clearly illustrates a linear relationship between the two variables, and also confirms the considerable grip and drive available from this pump configuration.

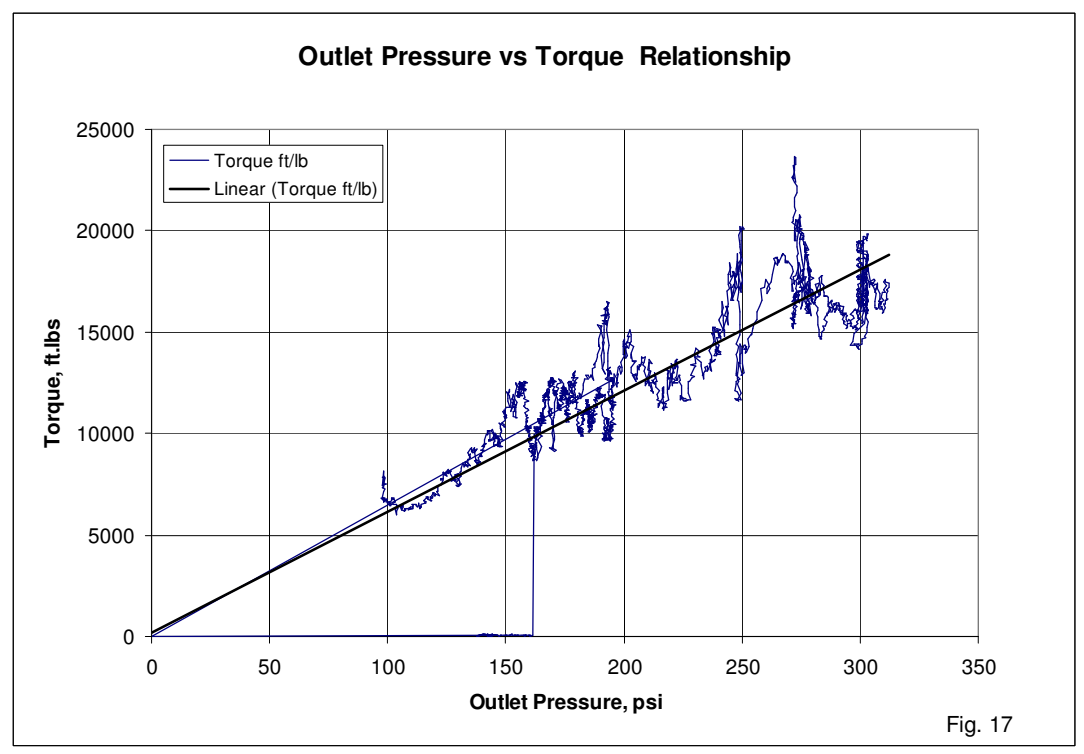

Fig.19 Relationship of Torque to Outlet Pressure. 
After achieving the target of pumping into $21 \mathrm{~kg} / \mathrm{cm}^{2}$ (300 psi) pressure, the test rig was transported to CQ Incorporated's larger facility in Homer City, PA. The equipment was installed and checked out in January 2004, and further extended test runs were made through the end of February 2004 to evaluate coal handling in winter conditions and test further outlet changes. Through the series of runs the torque requirement for the different geometries was monitored and some reduction was obtained. This is illustrated in Fig. 20, which shows the torque trend-lines for the first, last and an intermediate run illustrating the drop in torque requirement.

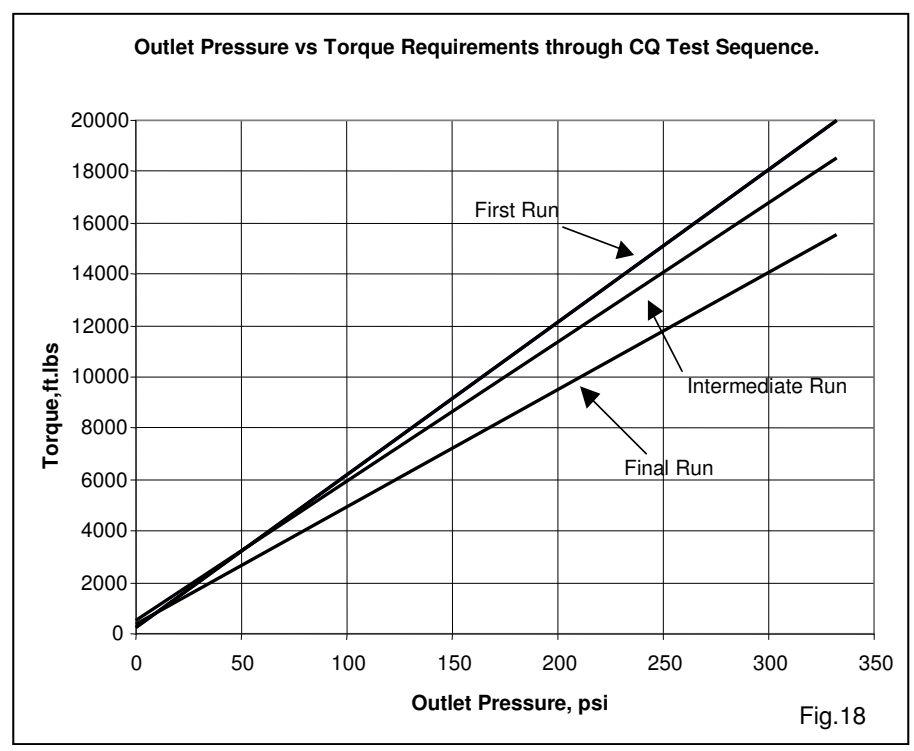

Fig.20 Torque Reductions Obtained in Phase 1.

\section{Phase 2 Testing:}

With a target of feeding coal into a gas pressure of $35 \mathrm{~kg} / \mathrm{cm}^{2}$ (500psi), the second phase focused on optimization, particularly in the outlet configuration, to reduce power requirements and loads in the pump. Instrumentation and monitoring equipment was also upgraded to provide more detailed data.

Modifications were made to the pump to allow visual monitoring of pump internals during operation by the use of clear polycarbonate components (Figure 21). While pressure capability in this mode was limited it provided better understanding of the mechanics of operation and flow regimes in the pump outlet. This knowledge was used to design and subsequently modify outlet inserts to achieve more optimal flow. 


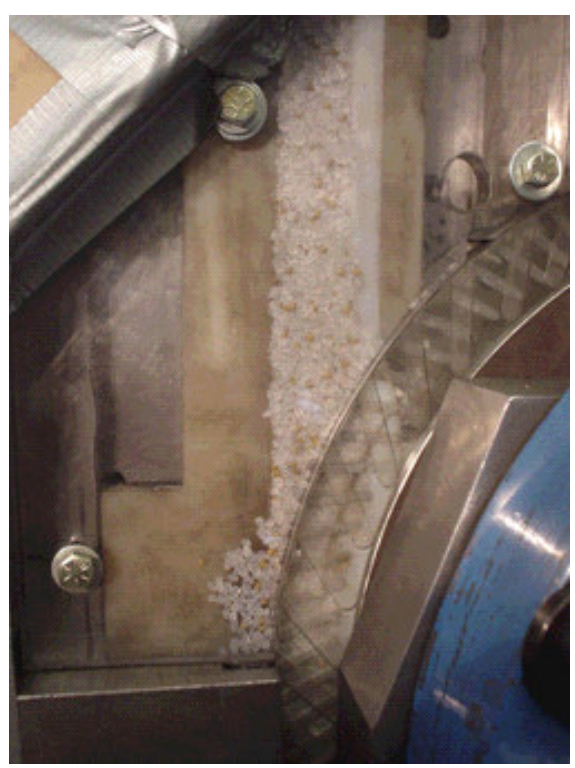

Fig.21 Flow Visualization Testing with Plastic pellets.

From this input the research team developed a number of modifications, particularly in the outlet area, that significantly reduced torque requirements. This area was the focus of considerable design and testing during this part of the program as visual flow tests indicated the majority of torque was being consumed in this region. Considerable testing was done to evaluate the flow in this region and develop geometry to optimize the flow.

A 3D outlet was manufactured in a reinforced nylon material by stereolithography. This enabled a complex optimized configuration in the transition from disc containment to outlet duct to be manufactured quickly and accurately directly from a computer generated solid model. This component was used for visual flow testing and then actual pumping with coal. This nylon duct worked so well that it was used for pressure tests. During testing the outlet was progressively shortened to determine effect on torque requirements and sealing capability. The result of this optimization process was that torque for a given pressure was reduced by 50-60 percent over the outlet configuration used for the phase 1 tests while still maintaining a stable seal. The $35 \mathrm{~kg} / \mathrm{cm}^{2}$ (500psi) pressure target was first achieved in January 2005 using this nylon outlet insert. Data from that test run is shown in Fig. 22. 
DE-FC26-02NT41439

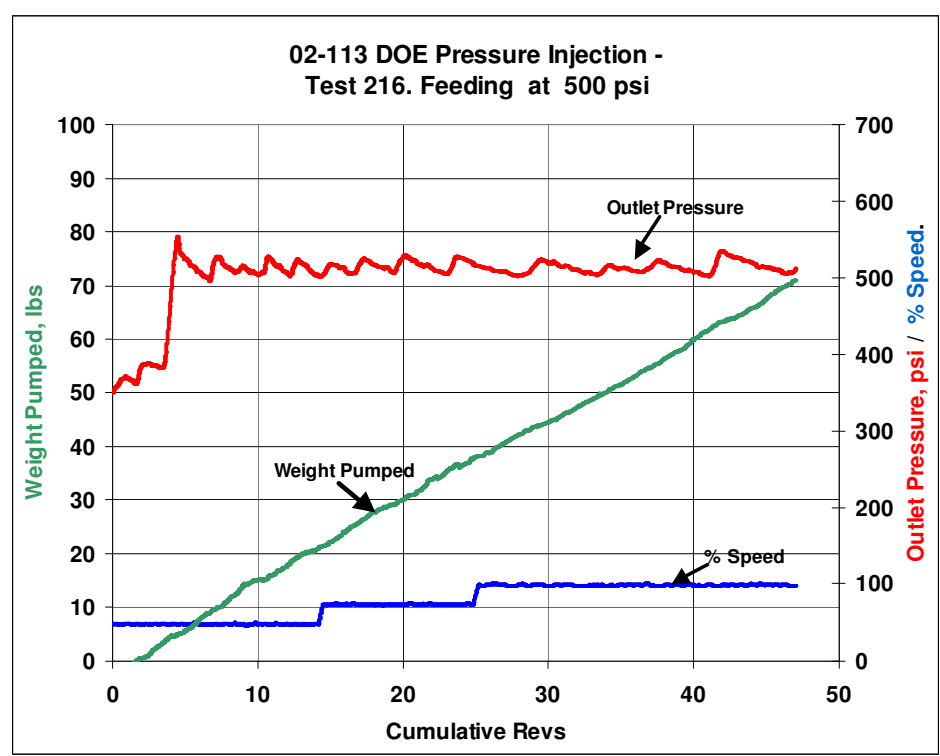

Fig.22 First Successful Run to $35 \mathrm{~kg} / \mathrm{cm}^{2}$ (500psi)

The Stamet Posimetric ${ }^{\circledR}$ feeder was subsequently operated repeatedly for durations exceeding two hours feeding into gas pressures at and above $35 \mathrm{~kg} / \mathrm{cm}^{2}$ (500psi). These runs also confirmed the ability of the pump to stop \& start under pressure while retaining a stable gas seal.

The overall torque reductions achieved from the beginning of the program to the end - over 50 percent - is shown in Figure 23. illustrating the major improvement in efficiency achieved during Phase 2.

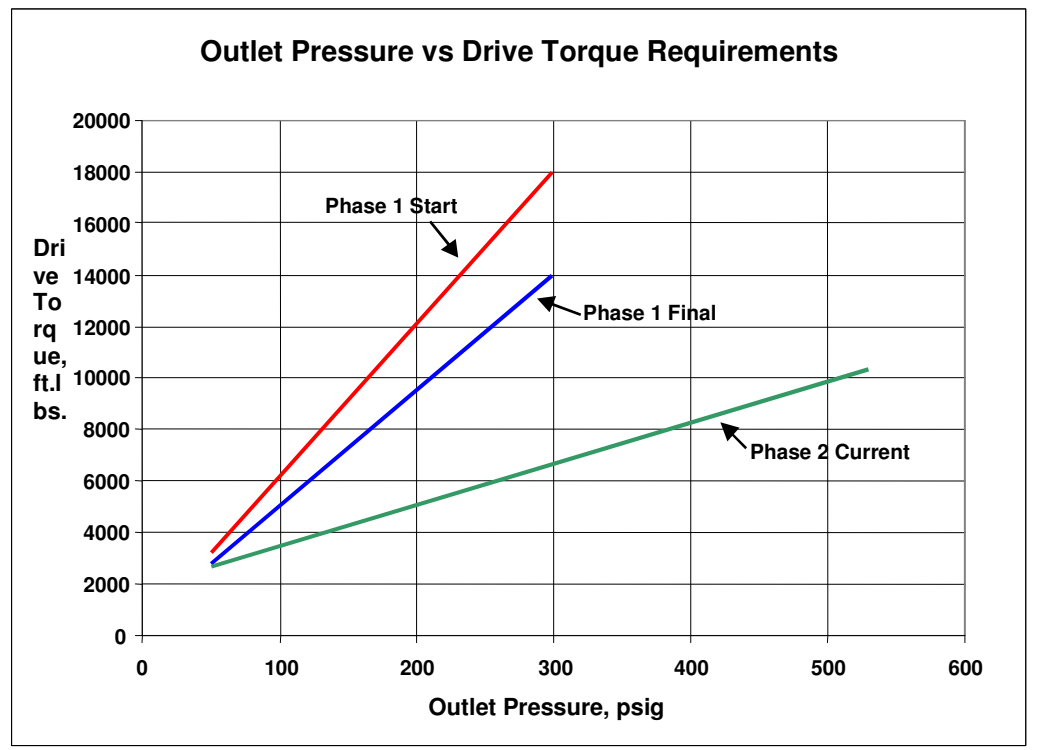

Fig.23 Torque Reductions Achieved.

Also of particular significance to practical applications, the operation of the feeder at these pressures saw very low requirements for make-up gas as shown in Figure 24. Typical make-up 
gas requirements were less than $5 \times 10^{-4} \mathrm{~m}^{3} / \mathrm{s}$. This would scale up in a commercial sized feeder, but level of flow still offers the significant benefit to gasifier operations of greatly reduced gas consumption over lock-hopper systems.

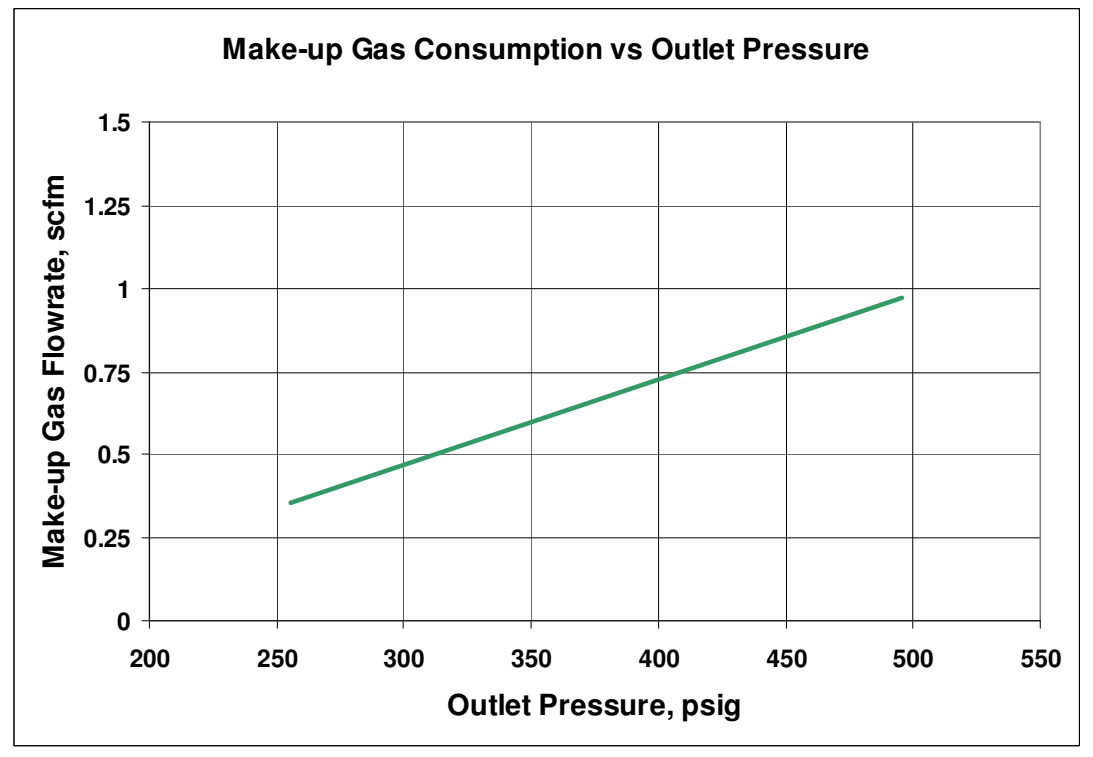

Fig.24 Make-up Gas Requirements

The phase 2 work successfully demonstrated the use of the Stamet Posimetric ${ }^{\circledR}$ High Pressure Solids Feeder System for feeding into gas pressures in excess of the $35 \mathrm{~kg} / \mathrm{cm}^{2}$ (500psi) target.

\section{Commercial Scale Feeder Estimates for 500psi Machine}

A deliverable for the program is a general design and cost estimate for a commercial scale highpressure feeder. Stamet has studied the results of the test program and in conjunction with industry gasification operators developed the expected configuration for a commercial feeder.

One major benefit of the Stamet Posimetric ${ }^{\circledR}$ feeder concept is its modularity, allowing multiple disc's to be assembled on a common shaft, in essence a series of feeders in parallel. This allows feed capacity to be increased in uniform increments and potentially has no upper limit other than practical machine size. The proposed commercial design is based on the multiple disc concept with the machine sized for expected gasifier feed requirements of $25 \mathrm{TPH}$, which is considered a nominal stepping-stone and building block for commercial systems.

Fig. 25 shows the conceptual feeder design layout for a commercial application, including inlet feed hopper and outlet transition. 


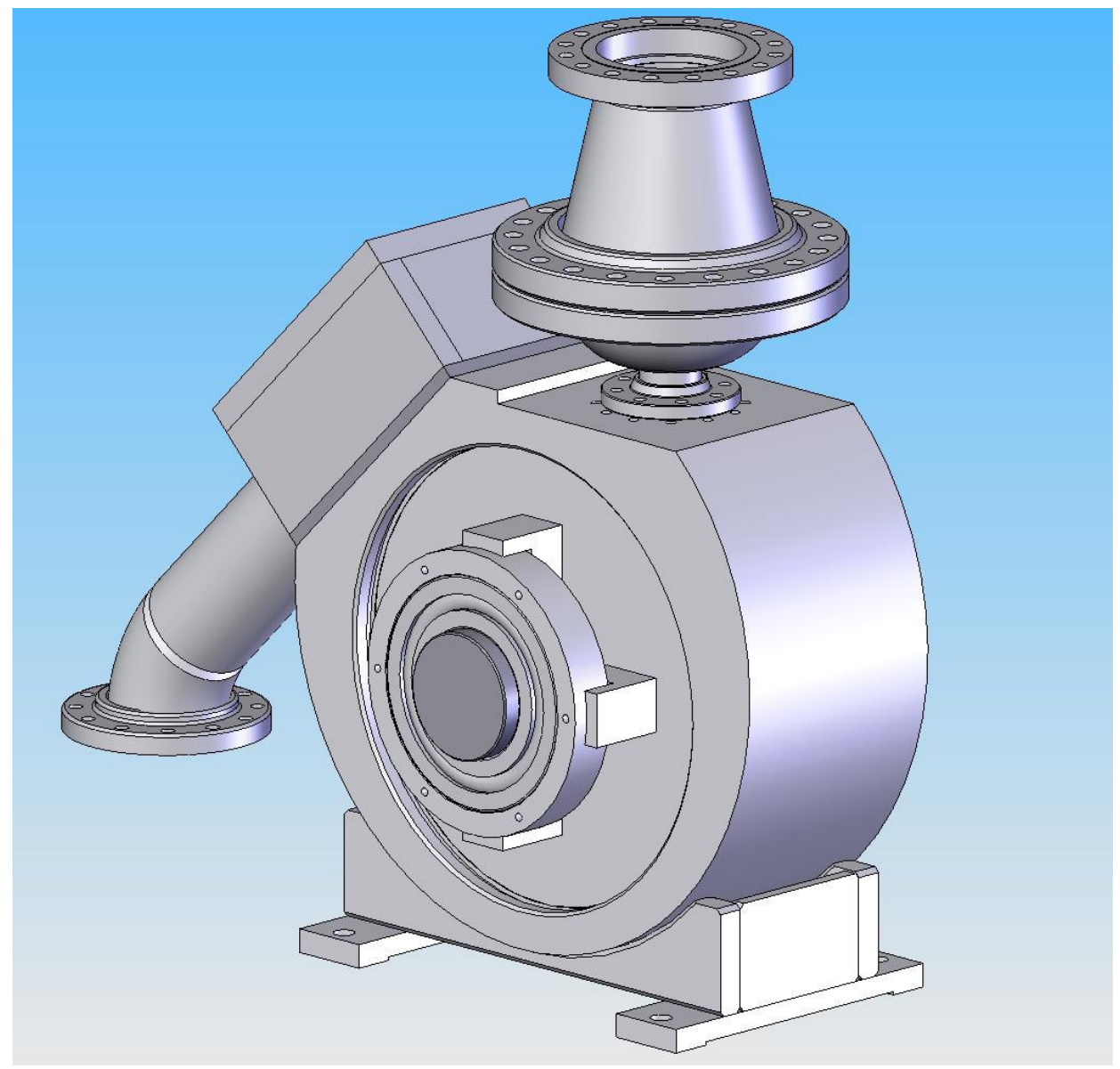

Fig. 25. Commercial Feeder Layout

Estimated specifications for a $25 \mathrm{TPH}$ feeder are as follows:

Feed rate for pre-pulverized PRB, Bituminous or Lignite fuel

$25 \mathrm{TPH}$

Fuel Size

Fuel Moisture Content

Disc diameter:

Number of Discs:

Pressure capability:

Feeder footprint:

Feeder Height:

Feeder Width:

Feeder Length:

Feeder Weight:

Motor Power:

Feeder Cost of Manufacture
$90 \%-200 \#$

$2-5 \%$

$1.5 \mathrm{~m}$

3

$35 \mathrm{~kg} / \mathrm{cm}^{2}$ (500psi)

$2 \mathrm{~m}$

$1 \mathrm{~m}$

$2 \mathrm{~m}$

$10 \mathrm{t}$

$200 \mathrm{~kW}$

\$350,000 (2Q2005 \$)

Other components that will be required as part of a feeder system will include inlet transition live-wall hopper, inlet transition pressure vessel, inlet isolating valve, outlet isolating valve and PLC control system. Cost for these components is estimated at $\$ 50,000$. 


\section{Phase III Testing:}

At the beginning of Phase I of the program a detailed evaluation of feed materials had been carried out. At that time a standard commercial grind of PRB was selected as the main feed material to be used in the program. A review of users carried out at the commencement of Phase III confirmed that in the interim commercial feedstock requirements had not changed significantly, so the commercial PRB grind was retained as the main feed material for this phase. Again, this was supplied by Power Systems Development Facility in Wilsonville, AL and used without any further processing. Other feed materials were tested to confirm pump operation with alternative feed-stocks, but the majority of the work was done with the commercial grind PRB coal.

Fig. 26 shows typical sieve analyses obtained for the PRB material as received.

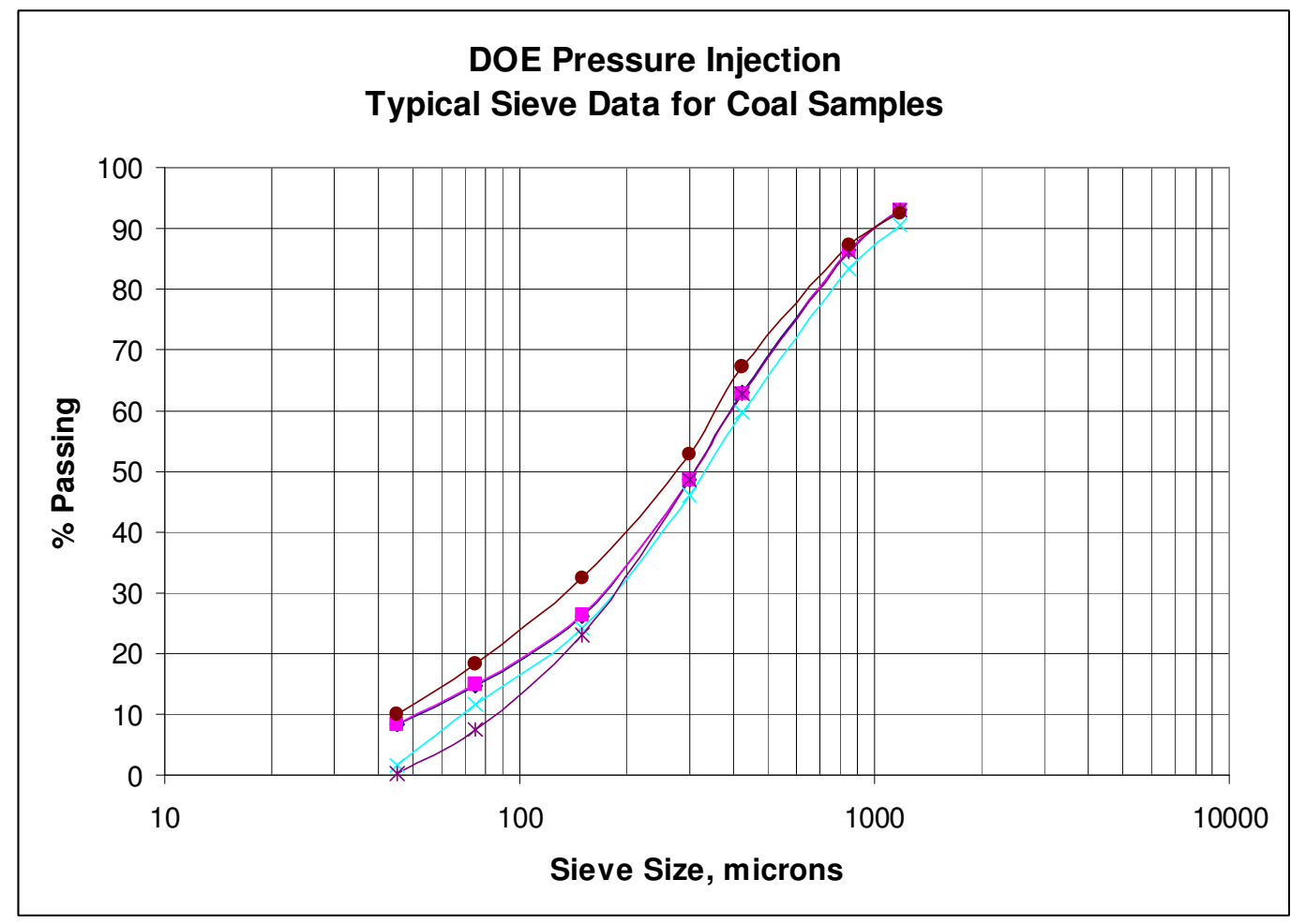

Fig. 26. Typical Sieve Analysis of as Received PRB.

Whilst the sieve analysis data showed some variation from batch to batch the overall data was consistent with the coal used in the earlier phases.

Upon completion of the pump design, manufacture and rig assembly, initial checks were carried out to confirm the basic functionality of the pump mechanicals and operation of the revised control and data acquisition systems. After initial shake-down all systems operated successfully and initial data was obtained on the basic torque characteristics of the pump as originally configured, both empty and feeding coal into atmospheric pressure at a range of speeds. The new test rig had been designed to allow the use of a symmetrical live-wall hopper design, unlike the Phase I \& II rig which had required an asymmetrical design to gain access to the pump inlet. 
This was expected to give improved inlet flow characteristics, and indeed the results demonstrated very consistent flow-rates across the full available speed range. Fig. 27 shows the very close agreement of theoretical and actual feed-rates obtained when feeding into atmospheric pressure across the full speed range available from the drive system $(0-5 \mathrm{rpm})$.

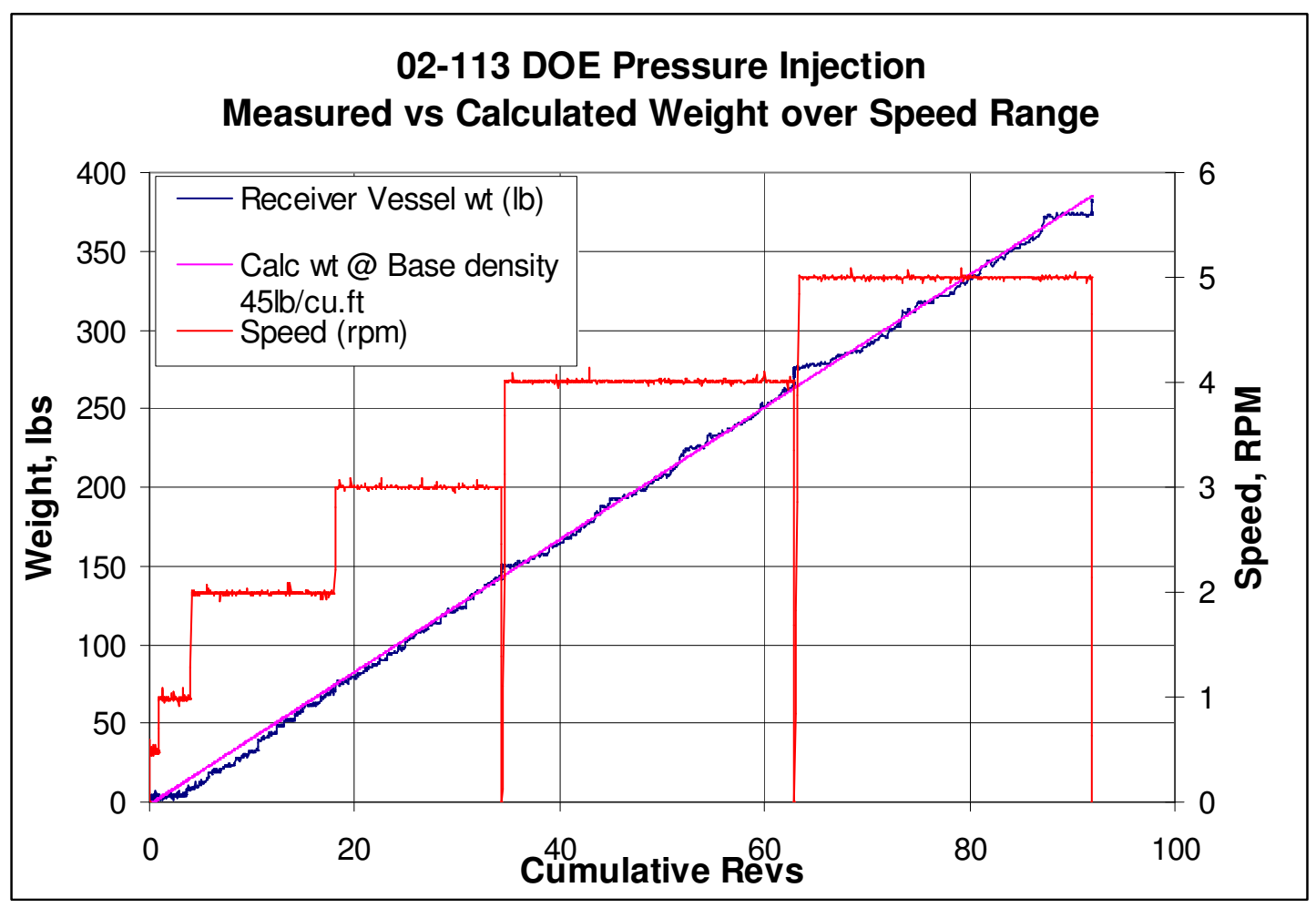

Fig. 27. Flowrate Comparison with Calculated across Speed Range.

After confirming adequate inlet feed capability, the feeder was run with a mechanical load blocking the outlet to confirm that sufficient grip was available from the design to allow feeding into the target pressure. The data obtained is shown in Fig. 28. This shows that available torque capacity exceeded 25,000 ft.lbs, and that material flow was maintained against an outlet resistance that required that level of torque to overcome. This was believed adequate to achieve the intended 1,000psi target. 


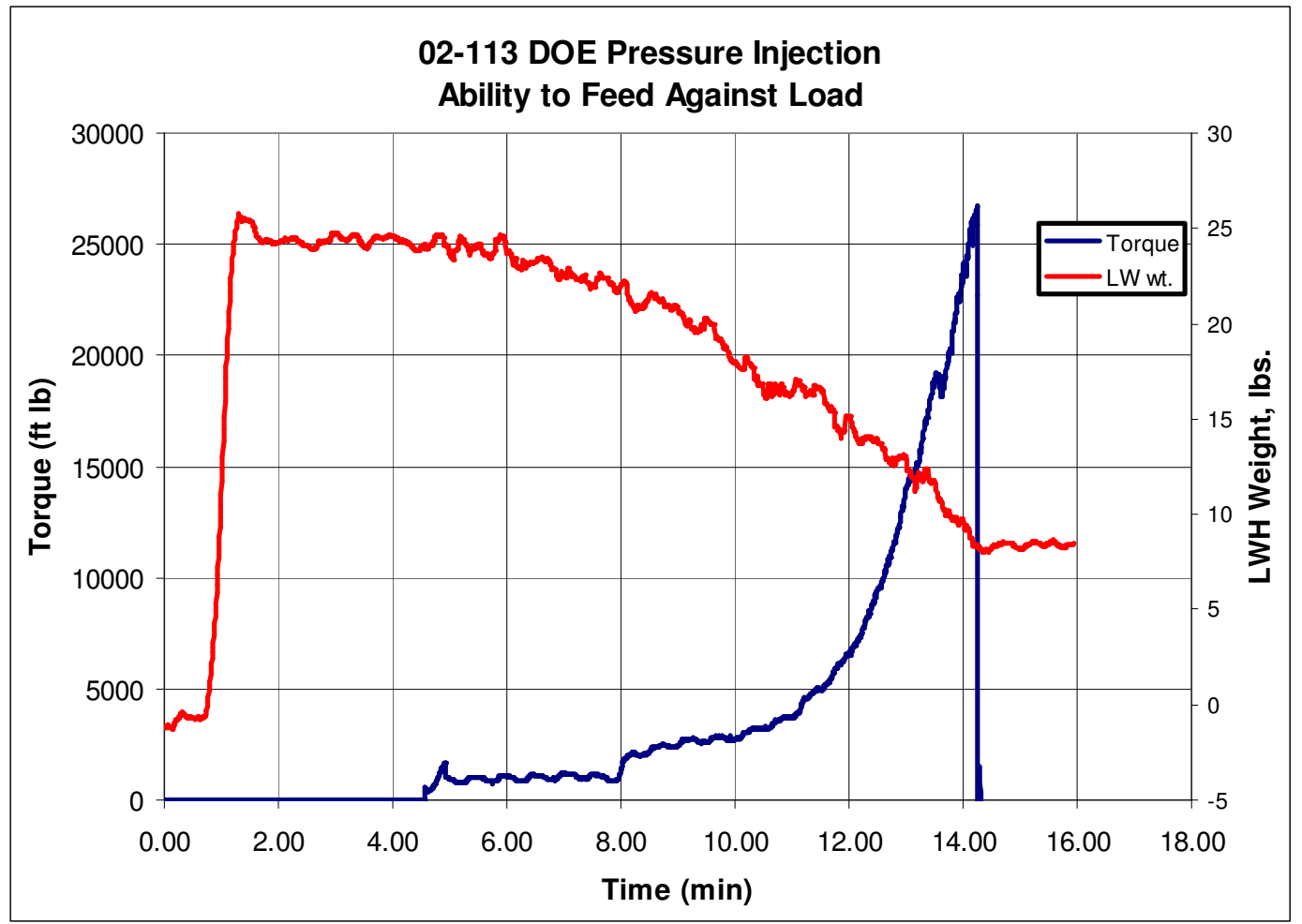

Fig. 28 Feeding Against a Mechanical Load.

An extended program of successive testing, feeder geometry modification and re-testing was then carried out in the Stamet facility in CA, feeding coal into progressively increasing pressure. This culminated in the successful feeding of coal into the Phase III target of $70 \mathrm{~kg} / \mathrm{cm}^{2}(1,000$ psi) gas pressure in March 2007.

Fig. 29 shows typical data obtained from a run up to 1,000psi. In this case an earlier run had been completed leaving a sealing plug of coal in the pump outlet, so the pressure was able to be brought up to 350psi before the machine was started. After starting the pump the pressure was steadily ramped up to $1,000 \mathrm{psi}$, during which time the torque steadily increased with the output pressure, and the pump continually fed coal into the receiver at a steady rate. 
DE-FC26-02NT41439

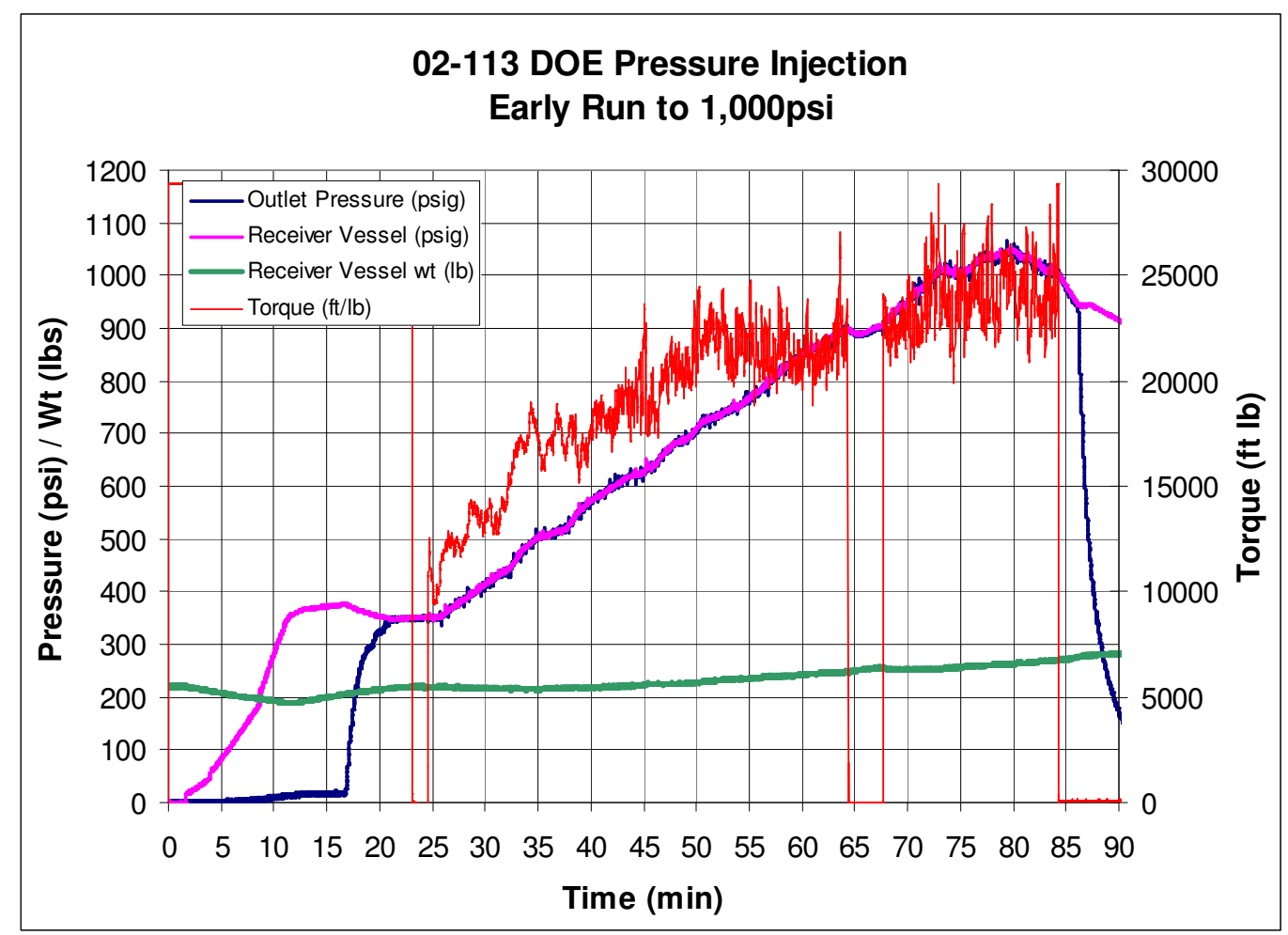

Fig. 29. Typical Data from Early Run into 1,000psig.

Close examination of the receiver weight readings shows some variations in the weight reading even before the pump was started. This was discovered to be an inherent error in the load cell reading associated with the pressure changes. The original receiver load cells were in-line diaphragm type, providing easy in-line mounting. When the pressure of the environment changed, the external pressure reacted on the load cell diaphragm area affecting the reading. Since the units were hermetically sealed, it had been anticipated that this effect could be corrected for based on the pressure applied. However, in practice it was found that the pressure effect was inconsistent and would balance out with time. This was presumably due to the load cell sealing being ineffective at high applied pressures, allowing some slight leakage into \& out of the units, changing the offset due to the applied pressure and resulting in some inconsistency in results. Subsequently the receiver load cells were changed to beam type to eliminate this effect. For earlier tests using these load cells, the load cell readings from the supply and LiveWall hoppers were available for comparison with the receiver weight data to avoid any large errors. 


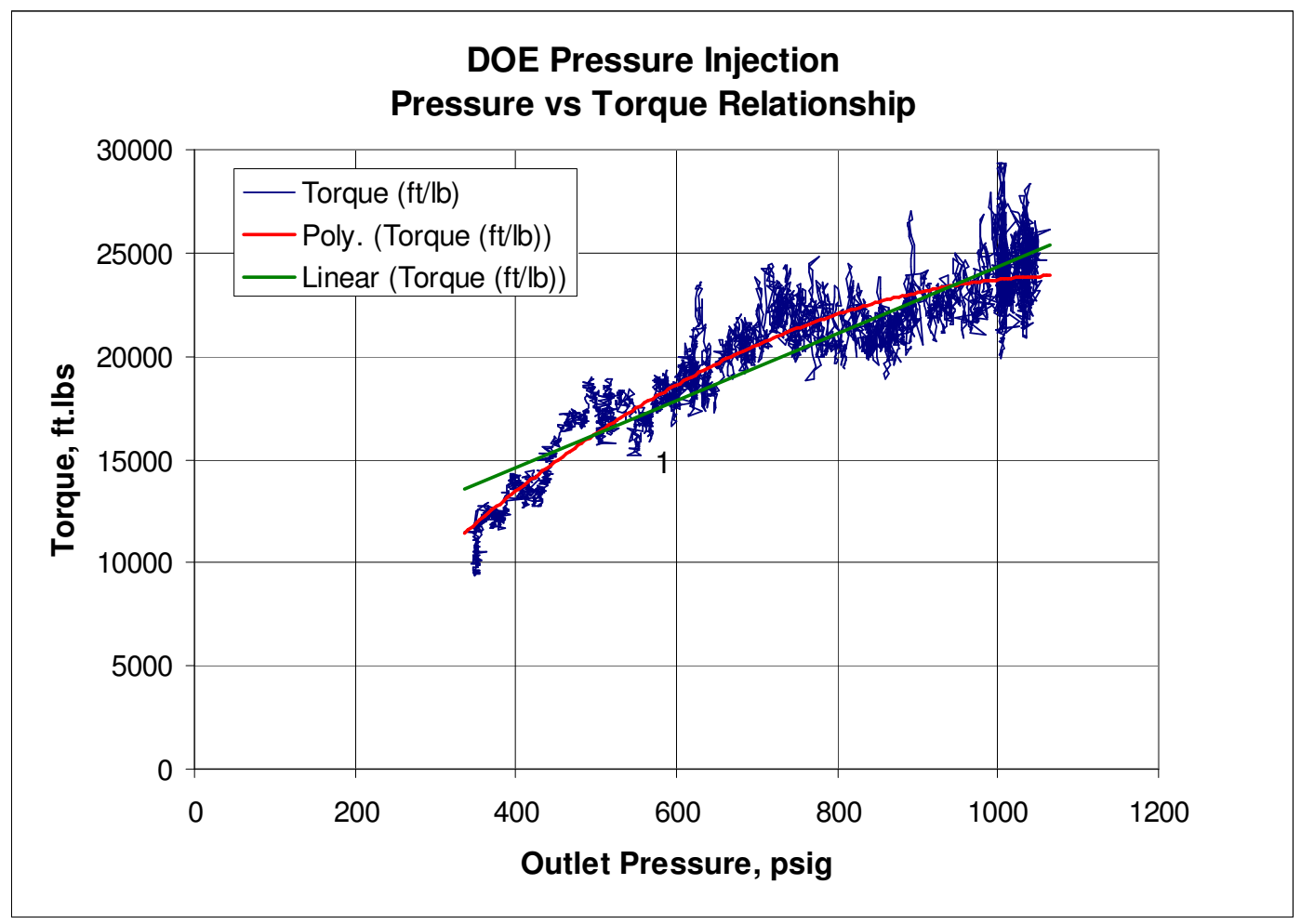

Fig. 30 Effect of Increasing Pressure on Torque Requirement.

Fig. 30 shows a typical relationship of the torque required to feed into the outlet pressure applied. As expected this increases with applied pressure, though at a less than linear rate as evidenced by the curve fits shown. Earlier tests at lower pressures had indicated a substantially linear torque increase with output pressure, but the slope appears to reduce at higher pressure levels. Further investigation of this effect would have been pursued in Phase IV of the program.

In comparison with the geometry of the Phase II pump, the Phase III pump has a larger diameter and a larger outlet pressure area, both of which would be expected to required a higher drive torque at a given outlet pressure. The final arrangements of the Phase II pump had achieved feeding into 500psi at a torque of approx.10,000 ft.lbs. Factoring in the diameter and area increases on the Phase III pump would predict a drive torque requirement of approx. 2.5 times that of the smaller Phase II pump at a given pressure condition. The actual measured torque values of less than 15,000 ft.lbs for the Phase III pump at 500psi, therefore represent a further efficiency improvement from the status at the end of Phase II. 


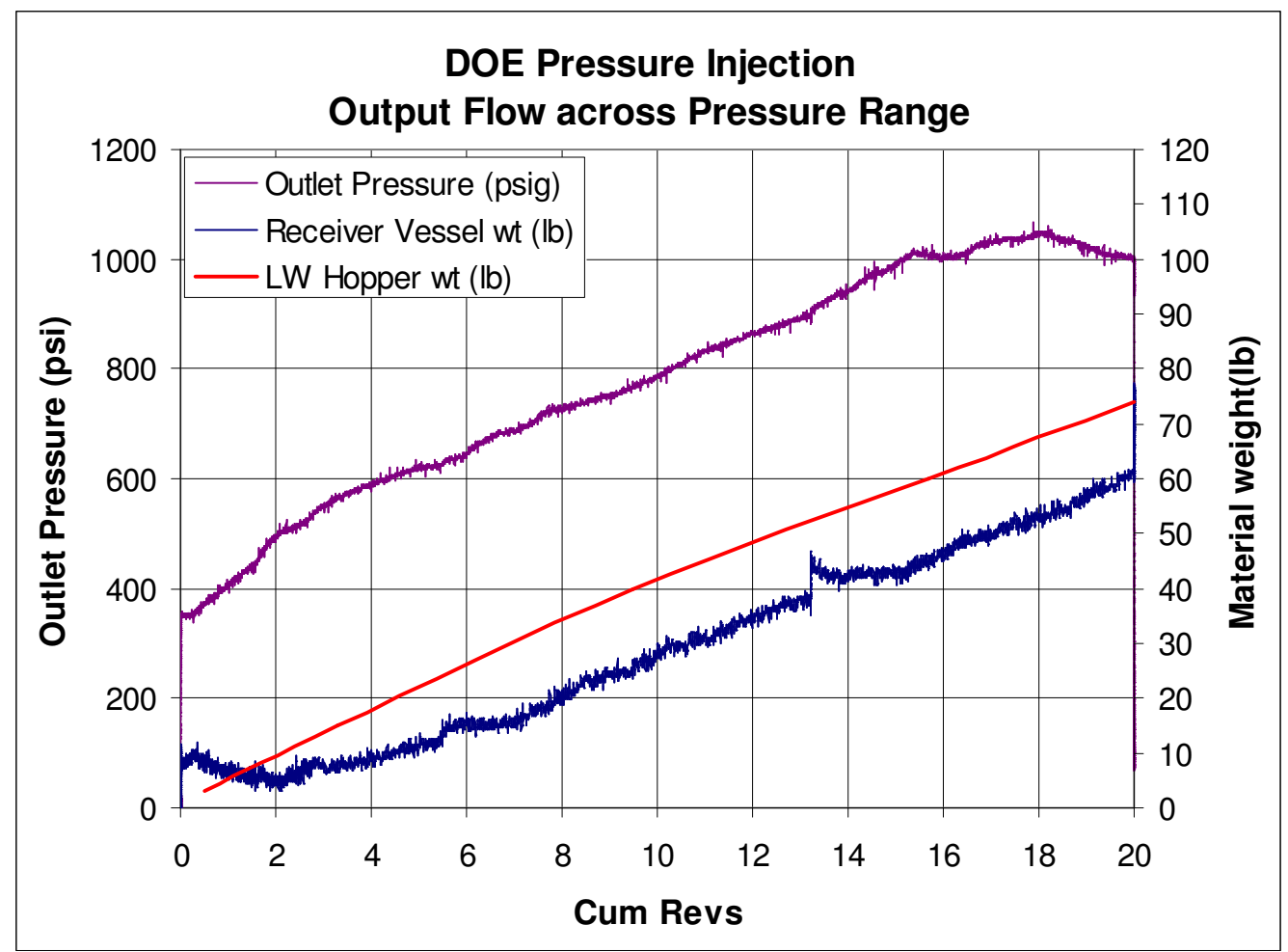

Fig. 31 Material Output Flow against Varying Pressure

Fig. 31 shows typical output flow recorded as the outlet pressure was increased. The weight pumped is plotted against cumulative revs, so that a straight line indicates constant throughput independent of the outlet pressure. This graph shows the recorded throughput measured both by loss in weight of the live-wall hopper on the inlet, and increase in weight of the receiver vessel on the outlet. Both show a generally straight line as the pressure changes. The lower overall level recorded in the receiver is accounted for by material filling the outlet transition at the start of the run before spilling over into the receiver vessel. At the end of the run approx $12 \mathrm{lbs}$ of material was held in the outlet transition, close to the measured difference between the two sets of readings. 


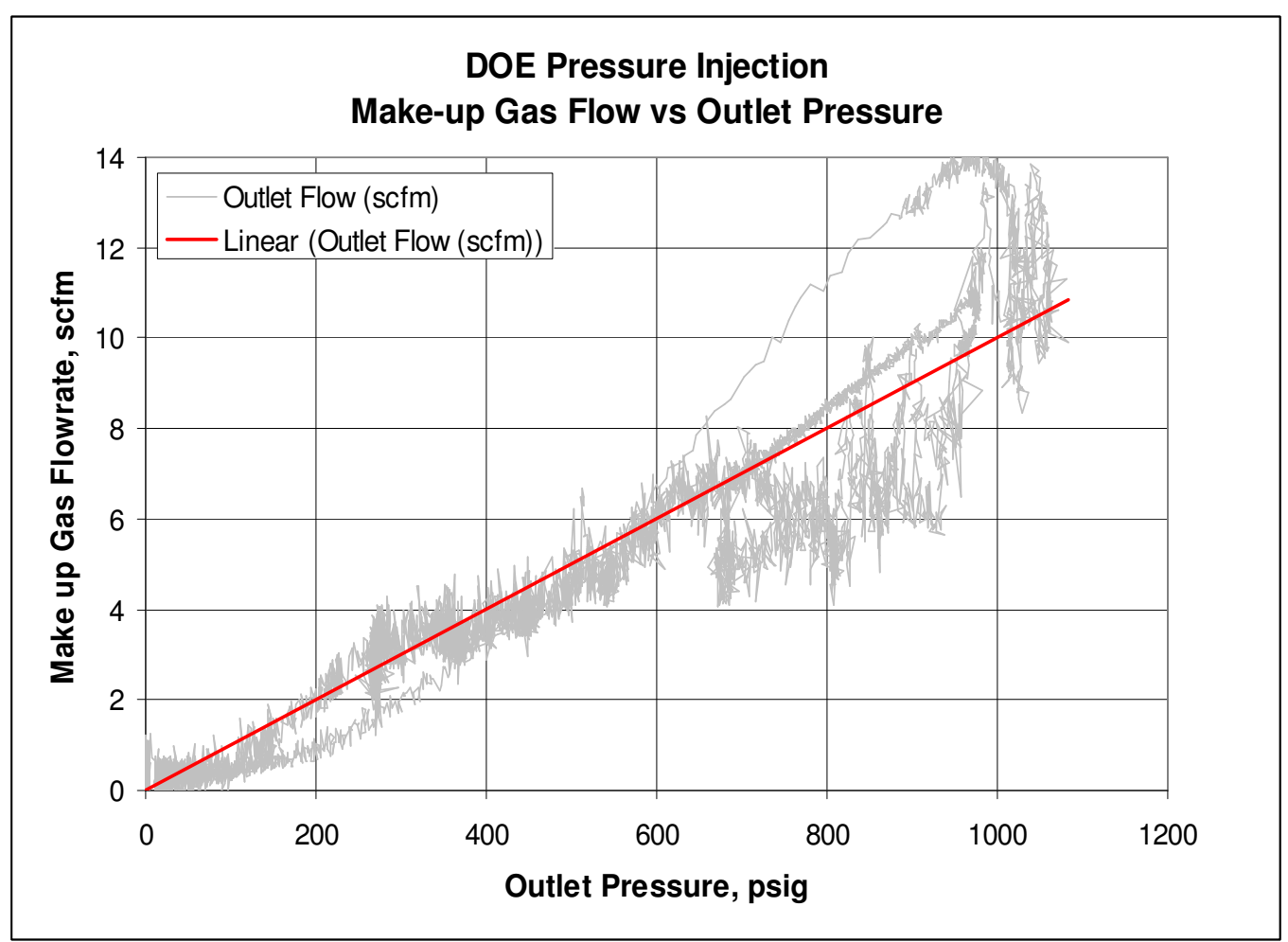

Fig. 32. Make-up Gas Requirements at Increasing Pressure.

Fig. 32 shows the amount of make-up gas required to maintain the outlet pressure through $1,000 \mathrm{psig}$. This shows gas requirements to increase generally linearly with pressure to a maximum of around $10 \mathrm{scfm}$ at $1,000 \mathrm{psig}$. The gas that permeated down the outlet plug was captured by ducted vents on the pump body and could be contained or redirected to other storage. The peak values up to $14 \mathrm{scfm}$ were measured when the pump was stopped with no outlet valve closed. The lower values were measured with the pump running and results generally showed total gas requirements reducing as pump speed increased. This is expected, since the rate of gas permeation down the pump outlet would be reduced by the movement of the sealing plug in the opposite direction. 


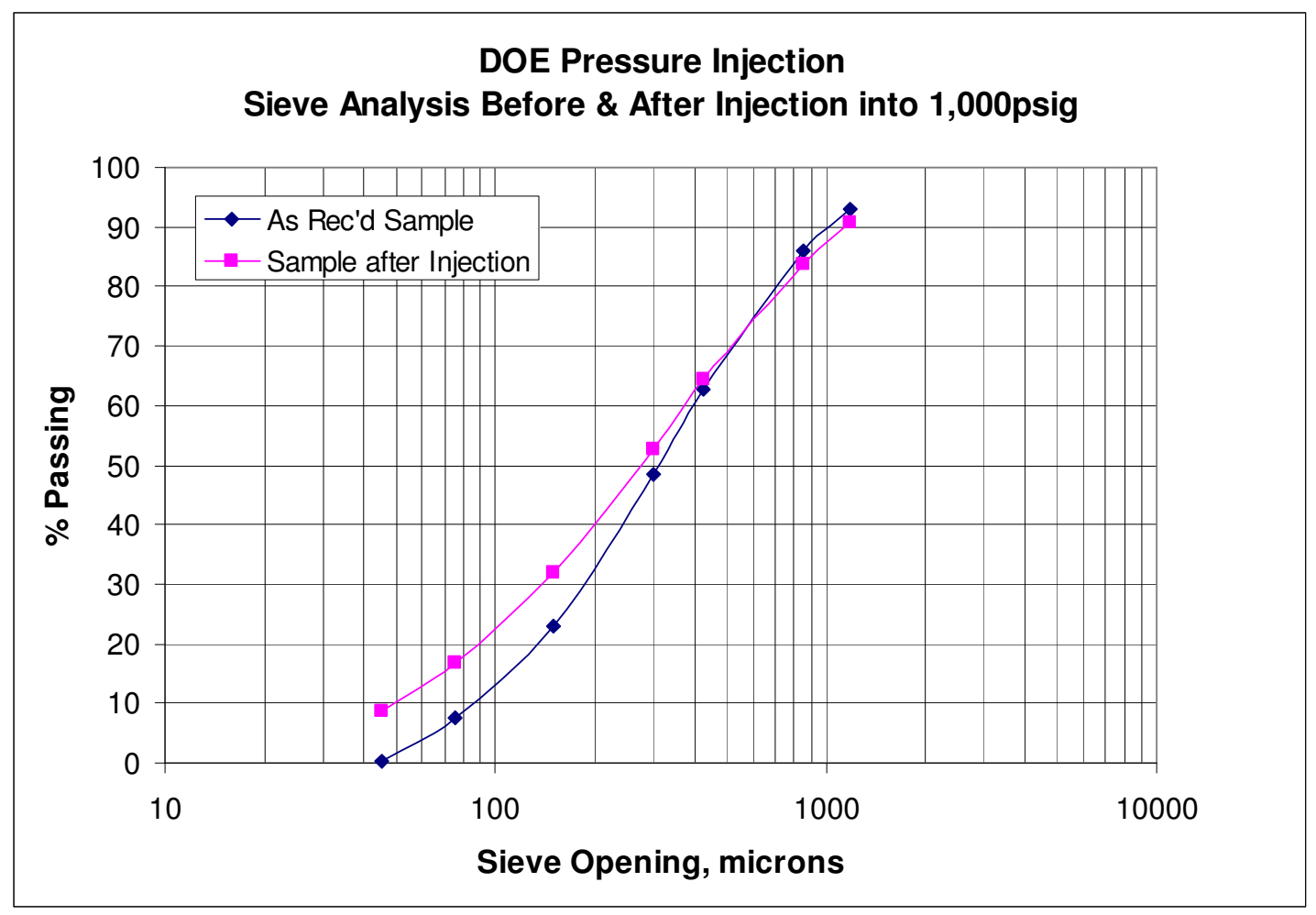

Fig. 33 Comparison of Sieve Analysis before and after Injection into 1,000psi.

Fig. 33 shows a comparison of typical sieve analysis data taken before and after an injection run into 1,000psi. This shows very similar distributions to that shown in Fig. 7 for the original as received material. The before and after comparison indicates that there is little agglomeration of material as it passes through the pump since there is very little change in the \% passing the larger sieve sizes. The increase in fines passing through the smaller sieves after injection suggests some attrition of particles during transit through the pump due to the forces applied. These results may vary with different source materials depending on particle hardness, original distribution etc. Further characterizations of this type would have been made if the project had continued. 


\section{Commercial Scale Feeder Estimates for 1,000psi Machine}

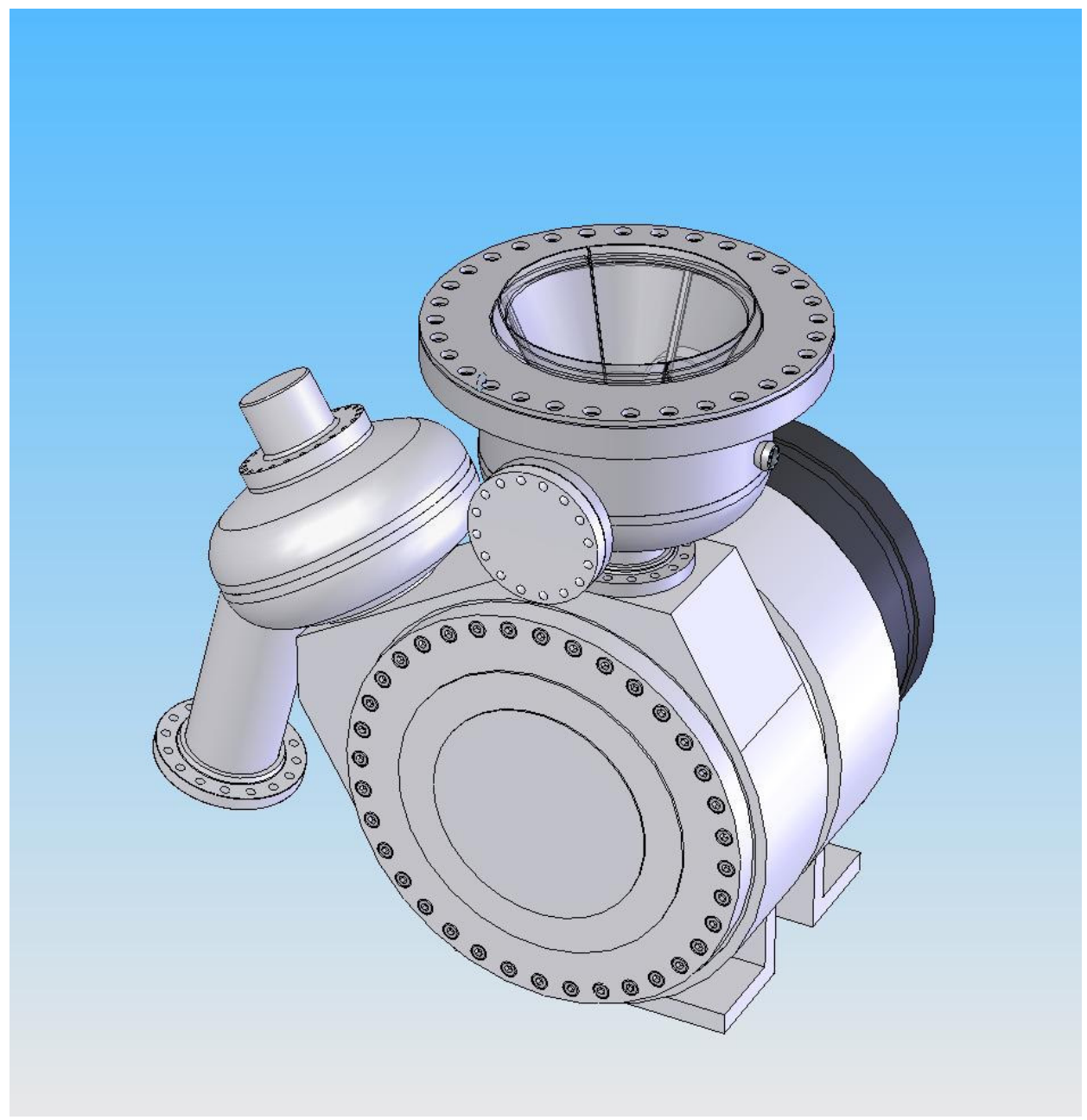

Fig. 34. Commercial Feeder Layout

Estimated specifications for a $30 \mathrm{TPH}$ feeder are as follows:

Feed rate for pre-pulverized PRB, Bituminous or Lignite fuel

$30 \mathrm{TPH}$

Fuel Size

$50 \%-100 \#$

Fuel Moisture Content

$2-16 \%$

Disc diameter:

$1.5 \mathrm{~m}$

Number of Discs:

4

Pressure capability:

$70 \mathrm{~kg} / \mathrm{cm}^{2}(1,000 \mathrm{psi})$

Feeder footprint:

Feeder Height:

$3 \mathrm{~m}$

Feeder Length:

$2 \mathrm{~m}$ 
DE-FC26-02NT41439

Feeder Width:

$1.2 \mathrm{~m}$

Feeder Weight:

$15 \mathrm{t}$

Motor Power:

$350 \mathrm{~kW}$

Feeder Cost of Manufacture

$\$ 550,000^{*}$

Other components required as part of a feeder system will include inlet transition live-wall hopper and inlet transition pressure vessel, inlet isolating valve, outlet isolating valve and PLC control system. Cost for these components is estimated at $\$ 75,000^{*}$.

*2Q2007 \$. Actual costs will be dependent on specification requirements and manufacturing volume

\section{Phase V Preliminary Design:}

Phase $\mathrm{V}$ of the program for the design, installation and long-term testing of a commercial scale feeder was approved in October 2006. The intent was to install the feeder at the PSDF in Wilsonville, $\mathrm{Al}$ where it could be operated both off-line and coupled to an operating gasifier.

Meetings with PSDF personnel confirmed design specifications applicable to commercial feeder design and installation, including but not limited to safety standards, design codes for pressure containment and hazardous environmental considerations applicable to the plant. The maximum feed rate of coal that the PSDF system could absorb was determined to be 10 tph, so this was the machine size selected for the program. Since this was to be the first installation of its type and would be coupled to an operating gasifier, it was determined from safety considerations that a pressure vessel would be provided on the inlet side of the feeder so that the system could be isolated while still in operation, in a similar manner to the test rigs used in the earlier phases. To maximize operational flexibility the vessel was sized to contain a $1 \mathrm{hr}$ buffer of feed material, and configured to fit into the selected location in the plant. The control logic and instrumentation necessary to control the feeder and integrate it with the PSDF DCS system was identified.

Based on the identified criteria the design for a large-scale feeder and ancillary equipment capable of continuous injection of pulverized coal into 550psi at a rate of 10tph for the planned test duration of over $1,000 \mathrm{hrs}$ was begun. Drive systems were evaluated and a hydraulic drive system selected for the feeder. Since this was a long lead item the drive system was placed on order. The basic layout and configuration of the feeder was defined, and preliminary solid models and drawings were produced for review. Investigations into availability of materials and other manufacturing considerations resulted in design modifications being implemented to enable feeder production to be completed within the quoted inlet vessel delivery timeframe of 26 weeks.

At this point in the work, the Stamet Posimetric ${ }^{\circledR}$ Feeder Technology was acquired by GE Energy LLC and work on the program ceased. Fig. 35 shows a view of the system as it was proposed at the time the design work was suspended, indicating the overall scale and close coupled hydraulic drive motor arrangement. 
DE-FC26-02NT41439

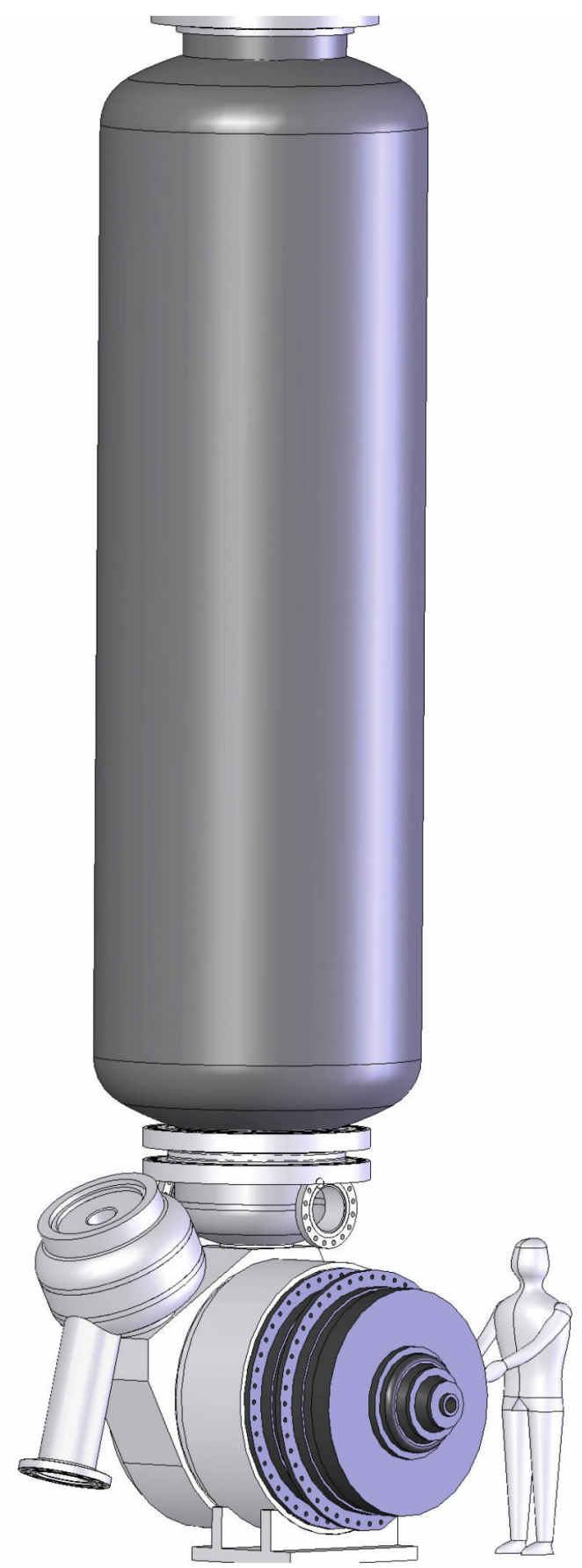

Fig. 35. General Arrangement of the Proposed Phase V Feeder 
DE-FC26-02NT41439

\section{Conclusions.}

The program successfully demonstrated the ability of the Stamet Posimetric ${ }^{\circledR}$ High Pressure Solids Feeder System to feed dry granular coal into pressures exceeding the $70 \mathrm{~kg} / \mathrm{cm}^{2}(1,000 \mathrm{psi})$ target.

The pumps were able to stop \& start under load while retaining a stable gas seal.

Material feed-rate was shown to be proportional to pump speed, and independent of output pressure.

The requirements for make-up gas were very small compared with usage in existing lock-hopper systems.

Design, installation and control integration details were produced for a 10tph, 550psi feeder for use in a long-term demonstration test.

A general design and preliminary cost estimate for a commercial-scale feeder capable of $25 \mathrm{tph}$ into $35 \mathrm{~kg} / \mathrm{cm}^{2}$ (500psi) of pressure was generated, indicating unit costs of the order of $\$ 350,000$ (2Q2005 \$). A general design and preliminary cost estimate for a commercial-scale feeder capable of $30 \mathrm{tph}$ into $70 \mathrm{~kg} / \mathrm{cm}^{2}$ (1,000psi) of pressure was generated, indicating unit costs of the order of $\$ 550,000(2 \mathrm{Q} 2007 \$)$. 